\title{
Caracterização geológica e geoquímica das intrusões de rochas metamáficas e félsicas nos mármores do Sul do Espírito Santo
}

\author{
Cícera Neysi de Almeida ${ }^{1^{*}}$, Edson Farias Mello ${ }^{2}$, Deonel Mandu Izaque ${ }^{3}$ e Pedro Douglas da Silva ${ }^{3}$
}

\begin{abstract}
Resumo Uma grande quantidade de rochas félsicas e metamáficas ocorre como lentes concordantes ou como intrusões tabulares concordantes ou discordantes em mármores do Grupo Paraíba do Sul, na região Sul do Espírito Santo. As rochas félsicas compreendem dois litotipos: monzogranito e sienogranito. Os monzogranitos apresentam características típicas da série cálcio-alcalino e os sienogranitos, de assinaturas alcalinas pós-colisionais, enquanto que as rochas metamáficas intrudidas nos mármores incluem basaltos e basaltos andesíticos cálcio-alcalinos e do tipo MORB-E. As rochas metamáficas e félsicas são remanescentes de três estágios magmáticos na história do Grupo Paraíba do Sul: a abertura da Bacia do Paraíba do Sul (MORB-E); a colisão durante a formação do Gondwana, representado pelo magmatismo básico cálcio-alcalino sin-Brasiliano e o final da orogênese brasiliana, registrada pelo magmatismo félsico, passando de cálcio-alcalino/cálcio-alcalino-K a alcalino, durante a fase de colapso do orógeno.
\end{abstract}

Palavras-chave: magmatismo félsico e básico; mármores; Complexo Paraíba do Sul; geoquímica.

Abstract Geological and geochemical characterization of mafic and felsic rocks intrusions in marbles from South of Espírito Santo State, Brazil. A great amount of metamafic and felsic rocks occurs as concordant or as concordant tabular concordant or discordant intrusions into marbles of Paraíba do Sul Group, in the South area of Espírito Santo State. Felsic rocks comprise two litotypes: monzogranite and syenogranite. The monzogranites have calc-alkaline signatures and the syenogranites present postcollision alkaline signatures, whereas the metamafic rocks included MORB-E and calc-alkaline basalts to basaltic andesites. Metamafic and felsic rocks are the remnants of three magmatic stages in Paraíba do Sul Group history: opening of Paraíba do Sul Basin (MORB-E); collision during Gondwana assembly, recorded by calc-alkaline basic magmatism; and the Brazilian (Pan-African) Orogeny closing, recorded by transition from high-K calc-alkaline/calc-alkaline to alkaline felsic magmatism during the orogen collapse.

Keywords: basic and felsic magmatism; marbles; Paraíba do Sul Group; geochemistry.

INTRODUÇÃO Diversas ocorrências de mármores no Sul do Espírito Santo se distribuem numa área de aproximadamente 180.000 ha, abrangendo os municípios de Cachoeiro de Itapemirim, Vargem Alta e Castelo, sendo que, em Cachoeiro e Vargem Alta, os mármores afloram continuamente, constituindo-se um maciço de cerca de $20 \times 8 \mathrm{~km}$, além de outros corpos com menores dimensões. Essa região é reconhecida como um dos principais polos produtores de mármores ornamentais do Brasil, contribuindo com uma produção bruta de $42.662 \mathrm{~m}^{3} \mathrm{em} \mathrm{2004}$, de um total de $52.537 \mathrm{~m}^{3}$ (DNPM 2006). A atividade extrativa encontra-se instalada há várias décadas, alimentando também as indústrias moageira e cimenteira. Em que pese a sua importância no cenário nacional, ainda são escassos os trabalhos de Geologia na escala de semidetalhe e detalhe. O objetivo deste trabalho consistiu em estudar as inúmeras intrusões de rochas félsicas e metamáficas, nestes mármores, com o foco em sua caracterização petrográfica e geoquímica.

\section{CONTEXTO GEOLÓGICO REGIONAL}

Enquadramento geotectônico A área estudada insere-se no Orógeno Araçuaí, tendo como coordenada inferior o paralelo $21^{\circ} \mathrm{S}$, considerando o limite entre os orógenos Araçuaí e Ribeira, devido ao fato de, nesta faixa, ocorrer a deflexão das estruturas que mudam da direção NNE a N no Araçuaí para NE no Orógeno Ribeira (Cunningham et al. 1998, Pedrosa Soares et al. 2001, Heilbron et al. 2004). Estes orógenos têm sua história evolutiva associada à Orogênese Brasiliana/Pan-Africana (Almeida et al. 1981, Heilbron et al. 2004).

\footnotetext{
${ }^{1}$ Departamento de Geologia, Instituto de Geociências - IGEO, Universidade Federal do Rio de Janeiro - UFRJ, Rio de Janeiro (RJ), Brasil.E-mail: neysi@geologia.ufrj.br

${ }^{2}$ Departamento de Geologia, Instituto de Geociências - IGEO, Universidade Federal do Rio de Janeiro - UFRJ, Secretaria de Geologia, Mineração e Transformação mineral, Ministério de Minas e Energia - MME, Brasília (DF), Brasil. E-mail: edson.mello@, mme.gov.br

${ }^{3}$ Curso de Graduação em Geologia, Instituto de Geociências - IGEO, Universidade Federal do Rio de Janeiro - UFRJ, Rio de Janeiro (RJ), Brasil.E-mail: pedrosalguod@yahoo.com.br

*Autor correspondente
} 
A Faixa/Orógeno Araçuaí (Almeida 1977, Pedrosa Soares \& Wiedemann-Leonardos 2000) compreende uma área dominada por rochas graníticas e metamórficas de alto grau, bordejando a margem SE do Cráton do São Francisco (CSF) entre os paralelos $15^{\circ}$ e $21^{\circ} \mathrm{S}$ (Inda \& Barbosa 1978, Siga Jr. et al. 1989, Almeida \& Hasui 1984, Pedrosa Soares \& Noce 1998). Está dividida/o em três domínios tectônicos: externo, interno e inflexão setentrional (Pedrosa Soares \& Wiedemann-Leonardos 2000).

O Domínio Externo, adjacente à borda $\mathrm{SE}$ do CSF, compreende uma faixa de dobramentos e empurrões com vergência Oeste, metamorfismo de fácies xisto verde a anfibolito baixo nas supracrustais e ausência de magmatismo orogênico (Pedrosa Soares \& Wiedemann-Leonardos 2000, Pedrosa Soares et al. 2001,2008,Alkmimet al. 2006). Oembasamento, constituído por complexos granítico-gnáissicos do Arqueano e Paleoproterozoico (Gouveia, Gunhães, Mantiqueira e Porteirinha) com remanescentes de greenstone belts, sequências supracrustais Paleoproterozoicas e granitos anorogênicos tardi-Paleoproterozoicos retrabalhados durante o Brasiliano (Figueiredo \& Teixeira 1996, Alkmim \& Marshak 1998, Noce et al. 1998), tem idade entre ca. 2.867 Ma a ca. 2.120 Ma (Silva et al. 2000, Heilbron et al. 2010). O Domínio Interno constitui o núcleo metamórfico-anatético do orógeno e caracteriza-se pela abundância de granitoides Neoproterozoicos a Cambrianos, incluindo a zona de sutura com remanescentes oceânicos e arco magmático cálcio-alcalino (Pedrosa Soares \& WiedemannLeonardos 2000, Pedrosa Soares et al. 2001, Heilbron et al. 2004). Neste domínio, o embasamento é representado pelos complexos Paleoproterozoicos Juiz de Fora e Pocrane e pelas bordas orientais dos complexos Gunhães e Mantiqueira. Dados isotópicos U-Pb no Complexo Juiz de Fora indicam idade de cristalização em ca. de $2.150 \mathrm{Ma}$ e de metamorfismo em $590 \mathrm{Ma}$ (Sölner et al. 1991). Idade U-Pb em zircão pelo método SHRIMP fornece idade de cristalização com ca. de $1.560 \mathrm{Ma}$ para rochas metamáficas do Complexo Pocrane (Silva et al. 2000), sendo assim correlacionado a eventos de rifteamento do CSF, marcados por atividades anorogênicas ao longo do sistema Espinhaço com idades nos intervalos 1,9-1,8; 1,7-1,3; 1,1-1,0; 0,9 e 0,7-0,6 Ga (Cordani et al. 1974, Teixeira 1985, Bastos Leal et al. 1994). A inflexão setentrional é o domínio em que a grande curvatura do Orógeno Araçuaí muda para Leste, guardando características dos dois outros domínios.
As sequências metassedimentares Neoproterozoicas ocorrem em todos os domínios, representadas pelos grupos Macaúbas, Dom Silvério, Rio Doce e Paraíba do Sul. O corpo carbonático, foco deste trabalho, encontra-se inserido neste último grupo.

Grupo Paraíba do Sul O Grupo Paraíba do Sul é uma unidade que se estende descontinuamente desde o Orógeno Ribeira ao Araçuaí. Compreende uma sucessão de rochas metapsamíticas e metapelíticas intercaladas por rochas calciossilicáticas, gonditos, quartzitos, mármores e rochas metamáficas. Mármore é a unidade característica dessa unidade, distinguindo-a dos domínios Andrelândia e Juiz de Fora, os quais incluem quartzitos e, mais raramente, calciossilicáticas (Heilbron \& Machado 2003).

Silva (1993) considera este conjunto de rochas como Complexo Paraíba do Sul, incluindo gnaisses intercalados por lentes de quartzitos, rochas calciossilicáticas, rochas metamáficas e mármores, verificando-se que a predominância em relação aos litotipos constituintes varia regionalmente, ora sendo mais abundantes as lentes de quartzitos e calciossilicáticas, as de rochas metamáficas e quartzito e ora os mármores e as rochas metamáficas. Essa variação na predominância dos litotipos levou Silva (1993) a dividir os paragnaisses do Grupo Paraíba do Sul em sete unidades distintas, denominadas: ps1, ps2, ps3, ps4, ps5, ps6 e ps7. Todo o conjunto apresenta-se cortado por veios de granitos, pegmatitos e diabásios e apresenta uma variação composicional do Sul para o Norte, marcada pelo aumento na quantidade de quartzito e ausência de gonditos.

O corpo carbonático do Sul do Espírito Santo insere-se na unidade ps 7 , reconhecida pela frequente presença de mármore e anfibolito e, subordinadamente, quartzito e calciossilicáticas em anfibóliobiotita gnaisse.

A abertura e o fechamento da Bacia do Paraíba do Sul, considerada do tipo margem passiva, foram inicialmente limitados entre 1,7 Ga (Ragatky et al. 2000) e $530 \mathrm{Ma}$ (Machado et al. 1996). Idades de rochas metamáficas, ocorrendo como lentes nesse grupo, apontaram ${ }^{87} \mathrm{Sr} /{ }^{86} \mathrm{Sr}$ consistentes com idade em torno de $840 \mathrm{Ma}$, considerada um intervalo mais preciso para a implantação da bacia (Ragatky et al. 2003). Isócrona em rocha total para os equivalentes metabásicos na Formação Ribeirão da Folha e para o ortognaisse granítico alcalino Salto da Divisa forneceram valores semelhantes (816 e $875 \mathrm{Ma}$, respectivamente) 
para a cristalização de tais rochas (Pedrosa Soares 1995, Silva et al. 2008). Cristais de zircão detríticos em gnaisses kinzigíticos forneceram dados $\mathrm{U}-\mathrm{Pb}$ (SHRIMP) que indicam fontes de diferentes idades, $631 \pm 19 \mathrm{Ma}, 774 \pm 13 \mathrm{Ma}$ e $2.104 \pm 12 \mathrm{Ma}$, para os protólitos sedimentares (Noce et al. 2004). A idade média ${ }^{207} \mathrm{~Pb} /{ }^{206} \mathrm{~Pb}$, limitando a máxima para a deposição desses protólitos em ca. $631 \mathrm{Ma}$, aponta as rochas do arco magmático como fonte para os sedimentos que se depositaram em uma bacia retroarco.

\section{Magmatismo no Orógeno Araçuaí A ativida-} de magmática no Orógeno Araçuaí é registrada por um grande número de intrusões básicas a ácidas Neoproterozoicas a Cambrianas (Wiedemann 1993, Wiedeman-Leonardos et al. 2002, Nalini Jr. 1997, Bilal et al. 2000, Noce et al. 2000, Pedrosa Soares et al. 1999, 2001, entre outros). Baseando-se nas similaridades petrológicas, geoquímicas e nos intervalos geocronológicos, Pedrosa Soares et al. (2011) definiram cinco supersuítes (G1, G2, G3, G4 e G5) associadas aos estágios pré-, sin-, tardi- e pós-colisional do Orógeno Araçuaí.

A supersuíte G1 é constituída por batólitos e stocks de composição tonalítica à granodiorítica, com enclaves microgranulares, apresentando subordinadamente granitos e microgranitos com alguns núcleos charnoquíticos a noríticos (Nalini Jr. 1997, Nalini Jr. et al. 2000, Pedrosa Soares \& WiedemannLeonardos 2000). Deformadas durante a Orogênese Brasiliana, as rochas da supersuíte G1 apresentam assinatura cálcio-alcalina de médio a alto-K, metaluminosa à peraluminosa. Os dados isotópicos estabelecem um intervalo de 630 a 590 Ma para este magmatismo que se deu durante a subducção de litosfera oceânica, formando um arco magmático ou uma margem continental em estágio pré-colisional (Nalini Jr. 1997, Wiedemann et al. 1997, Pedrosa Soares et al. 2001, 2010, Bilal et al. 2000).

A supersuíte G2, em sua maioria, é constituída por granitos tipo $\mathrm{S}$ e, em menor volume, tipo I gerados pela migmatização do embasamento Paleoproterozoico (Nalini Jr. et al. 2000, Pedrosa Soares \& Wiedemann-Leonardos 2000, Pinto et al. 2001, Noce et al. 2004). Apresenta evidências de geração de magmas a diferentes níveis crustais, desde granitos a duas micas relativamente pouco profundos à biotita granada granitos e charnoquitos encaixados em complexos sob fácies anfibolito-granulito (Pedrosa Soares 2010). Os granitos tipo S encontram- se tectonicamente foliados; contudo, onde a foliação magmática é preservada, esta se encontra paralela à foliação regional conferindo o caráter sintectônico de tais corpos intrusivos (Pedrosa Soares \& WiedemannLeonardos 2000, Nalini Jr. et al. 2000). Esta suíte está relacionada à anatexia regional ocorrida durante o espessamento crustal, constituindo, assim, o núcleo anatético sincolisional do Orógeno Araçuaí (Pedrosa Soares et al. 1999), limitado entre 585 a $560 \mathrm{Ma}$ (Nalini Jr. et al. 2000, Noce et al. 2000, Silva et al. 2000, Pedrosa Soares et al. 2008, 2011).

As rochas da supersuíte G3 consistem de leucogranitos com variadas proporções de granada e/ ou cordierita e/ou sillimanita, não deformados, ocorrendo como veios e pequenos stocks autóctones encaixados nas rochas da supersuíte G2. Composições enderbíticas a charnoquíticas são também verificadas (De Campos et al. 2004). Tais rochas representam um episódio de refusão dos granitos $\mathrm{G} 2$, tendo sido geradas no estágio tardicolisional relacionado à transição das fases finais de compressão e relaxamento crustal, limitado entre 540 a $525 \mathrm{Ma}$ (Noce et al. 2004, Pedrosa Soares et al. 2011).

A supersuíte G4 consiste principalmente de plutons alojados como balloons, zonados, compostos por biotita granito nos núcleos e raízes passando para granito a duas micas e muscovita-granito nas bordas, em que também se verifica a transição de foliação de fluxo para foliação no estado sólido (Pedrosa Soares \& Wiedemann-Leonardos 2000, Pedrosa Soares et al. 2001).

A supersuíte G5 consiste de corpos em forma de balloons, representados por dois estágios magmáticos: um precoce caracterizado por intrusões charnoquíticas e um bimodal variando de granitos e/ou charnoquitos a noritos/dioritos, que corresponde ao episódio magmático mais jovem da região (Pedrosa \& Wiedemann-Leonardos 2002, Wiedemann et al. 2002). Granodioritos, sieno a monzogranitos de textura fina à allanita, titanita e biotita, compõem as fácies mais tardias, intrudidas como soleiras, diques e/ou formando o envoltório mais externo dos plutons (Wiedemann et al. 2002). Apresentam assinatura cálcio-alcalina de alto-K e alto-Fe à alcalina, metaluminosos a levemente peraluminosos, tipos I a A, gerados durante o evento pós-colisional relacionado ao colapso gravitacional do Orógeno Araçuaí, ocorrido entre 520 a 480 Ma (Bayer et al. 1987, Wiedemann 1993, Faria 1997, Mendes et al. 1997, 2005, Celino et al. 2000, Pedrosa Soares et al. 2001, 2006, 2011). 
Aspectos de campo $\mathrm{Na}$ região estudada (Fig. 1), são predominantes as rochas carbonáticas, que compreendem dois tipos litológicos principais, mármores calcíticos e dolomíticos, ocorrendo como faixas espessas, intercaladas entre si formando um conspícuo bandamento composicional. Secundariamente, observa-se um bandamento metamórfico, marcado por níveis descontínuos de minerais silicáticos entre as bandas carbonáticas. Esses níveis silicáticos são constituídos por aglomerados de diopsídio ou tremolita ou pela associação destes dois minerais \pm olivina. Observam-se também minerais asbestiformes (tremolita fibrosa, antofilita, grunerita e crocidolita). As rochas metamáficas ocorrem sob a forma de diques (Fig. 2) com espessura variando de $20 \mathrm{~cm}$ a $1,5 \mathrm{~m}$, exibindo foliação concordante com as da rocha encaixante $(\mathrm{NW}-\mathrm{SE})$ e todo o conjunto forma diversos padrões de dobramento, tais como: dobras recumbentes, fechadas, apertadas e isoclinais e estruturas do tipo boudins nos seus flancos. As feições estruturais observadas sugerem que essas rochas e os mármores tenham sido submetidos aos mesmos eventos deformacionais e metamórficos. No contato com o mármore, tais feições desenvolvem auréolas de escarnitos, nas quais a calcita apresenta-se corada (amarela, cinza, preta, rosa e laranja).

As intrusões félsicas compreendem granitos que ocorrem sob a forma de diques e soleiras com espessuras variando de decimétricas a métricas (Fig. 2). Os diques preenchem fraturas ou falhas transcorrentes tardias WNW/SV, ora concordantes, ora discordantes ao bandamento do mármore ( $\mathrm{SE} / 30$ a $45^{\circ}$ ). O desenvolvimento de auréolas escarníticas também é observado no contato das intrusões graníticas. Neste caso, são ricas em calcita clara, diopsídio e olivina ( \pm wollastonita).

\section{PETROGRAFIA}

Intrusões metamáficas Possuem granulação fina à média, textura lepidoblástica, de foliação contínua e definida pela orientação preferencial de clinopiroxênio, ortopiroxênio, anfibólio, biotita e/ou flogopita. Verifica-se também um bandamento composicional, marcado pela intercalação dos níveis enriquecidos nos minerais prismáticos/lamelares e daqueles em plagioclásio. A análise petrográfica permitiu determinar que as intrusões metamáficas foram submetidas a metamorfismo em fácies granulito e anfibolito, com caráter retrometamórfico em fácies xisto verde.

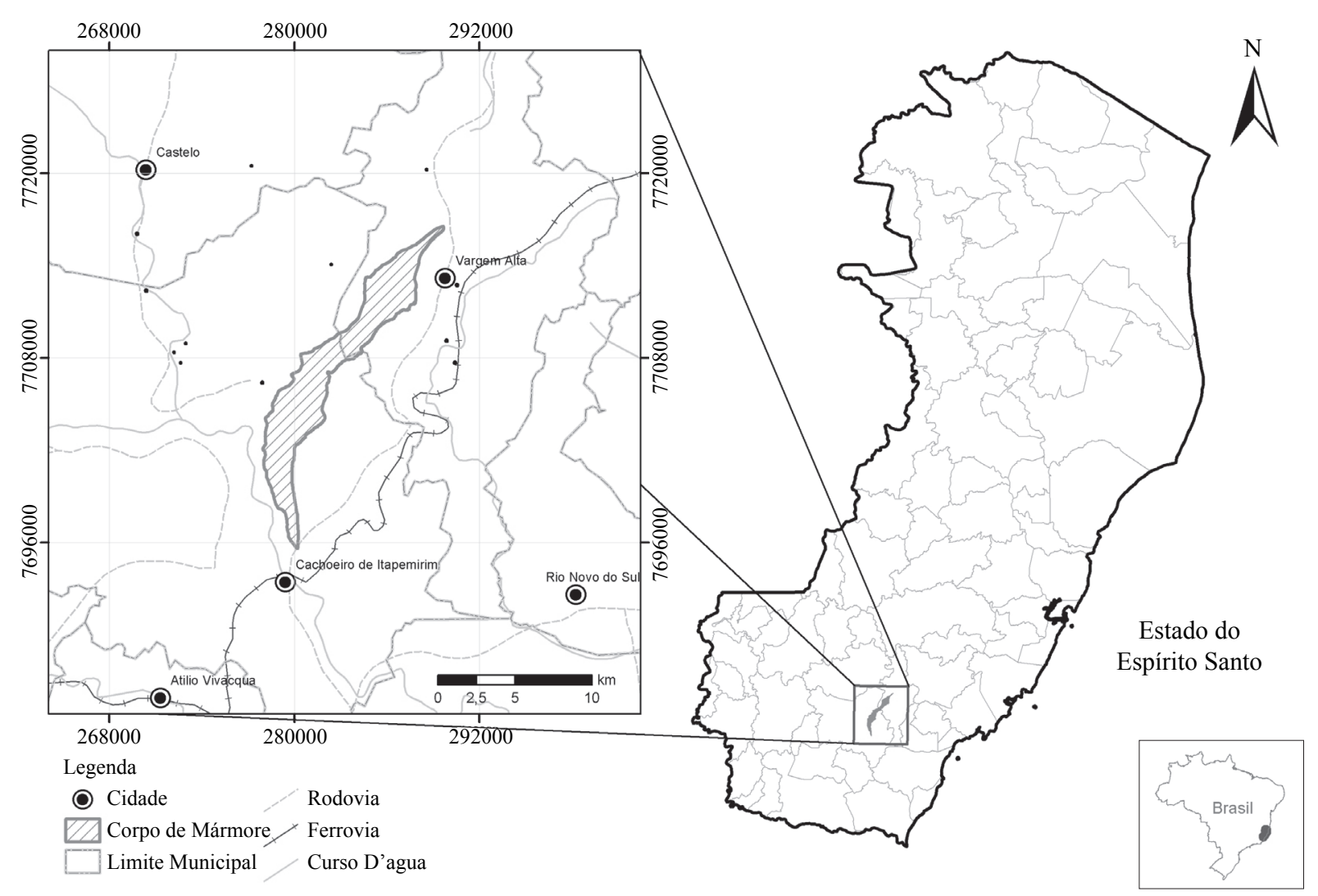

Figura 1-Mapa de localização do corpo carbonático do Sul do Espírito Santo (Fonte: Silva et al. 1993; modificado). 


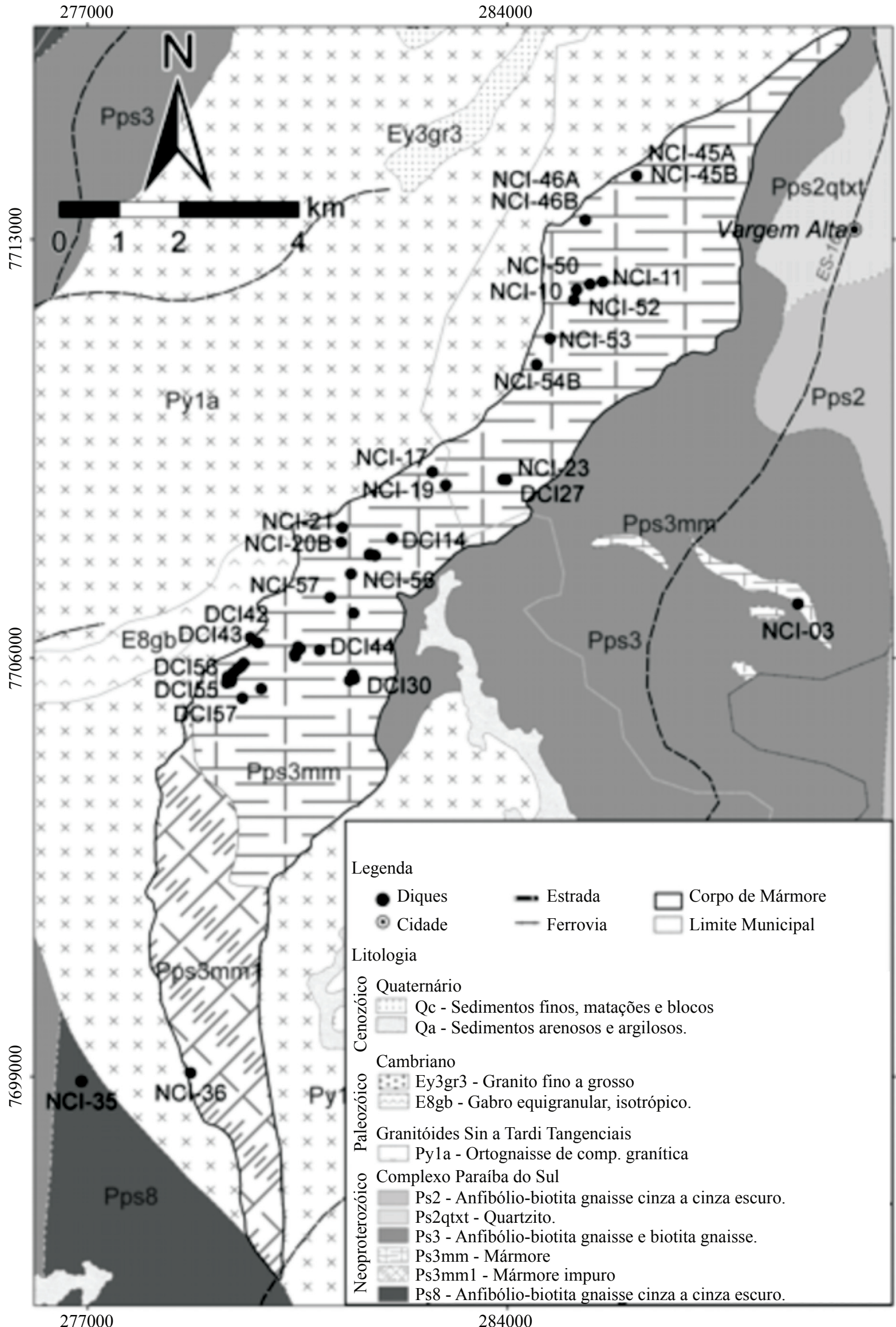

Figura 2 - Esboço geológico da região Sul do Espírito Santo com a localização dos diques de rochas metamáficas e félsicas estudadas. 
FÁCIES GRANULITO Aassociação mineral que define a fácies granulito é composta por ortopiroxênio, clinopiroxênio, plagioclásio e hornblenda. Quartzo, flogopita, titanita, zircão e opacos ocorrem como minerais acessórios. Os minerais retrometamórficos são epidoto, sericita, escapolita e clorita. O clinopiroxênio (diopsídio) ocorre como cristais prismáticos subédricos, variando de 0,3 a $0,5 \mathrm{~mm}$ em forma de agregados e em grãos isolados mantendo contatos retos com ortopiroxênio, o que indica equilíbrio metamórfico. O ortopiroxênio (hiperstênio) apresenta-se como cristais subédricos variando de 0,3 a 1,3 mm. O plagioclásio ocorre como cristais prismáticos, subédricos, com dimensões variando de 0,2 a $0,4 \mathrm{~mm}$ e se encontra parcialmente substituído por escapolita, epidoto e sericita. A hornblenda ocorre em hábito prismático, subédrica, com dimensões variando de 0,5 a $0,9 \mathrm{~mm}$, mantendo contatos retos a lobados com os demais minerais. O quartzo é levemente fraturado, ocorrendo como grãos anédricos, com dimensões variando de 0,3 a $0,5 \mathrm{~mm}$, em grãos isolados e em agregados. Em alguns cristais, observa-se um núcleo bem preservado e bordas recristalizadas de novos grãos.

A flogopita apresenta pleocroísmo variando de marrom claro a escuro, ocorrendo em hábito lamelar. É subédrica com dimensões em média variando de 0,4 a $1,1 \mathrm{~mm}$, orientada preferencialmente em apenas uma direção. Encontra-se parcialmente alterada para clorita. A titanita ocorre como inclusões parciais no clinopiroxênio. $\mathrm{O}$ zircão é euédrico e sempre se apresenta como inclusão no quartzo. Os opacos são anédricos, com hábito granular, ocorrendo em grãos isolados. Segundo Yardley (1994), paragêneses minerais constituídas por clinopiroxênio, ortopiroxênio e plagioclásio são estáveis em pressão de 5 kbar e temperatura média de $900^{\circ} \mathrm{C}$, indicando condições de fácies granulito de baixa pressão.

FÁCIES ANFIBOLITO Nas rochas estudadas, as condições metamórficas sob fácies anfibolito foram determinadas pela associação mineral hornblenda, plagioclásio, biotita e clinopiroxênio. Os acessórios são quartzo, zircão, opacos e titanita. Os minerais de alteração retrometamórfica são epidoto, sericita, tremolita, clinozoisita e calcita. Apresentam uma foliação definida pela orientação preferencial dos minerais máficos, podendo-se também observar um bandamento composicional incipiente, marcado pela intercalação de níveis ora mais ricos em anfibólio/ biotita e outros ricos em plagioclásio.
A hornblenda apresenta-se como cristais subédricos entre 0,1 e $0,4 \mathrm{~mm}$, ocorrendo em cristais isolados e em agregados com a biotita e minerais opacos. Os grãos de plagioclásio são, em geral, subédricos, às vezes, anédricos, com hábitos tabulares em torno de 0,3 a $1,6 \mathrm{~mm}$. O clinopiroxênio (diopsídio) ocorre em hábito prismático, subédrico, variando de 0,5 a $1,0 \mathrm{~mm}$, mantendo contatos retos a graduais com a hornblenda, o que indica desestabilização do primeiro. O quartzo é representado por grãos anédricos, compostos por um núcleo bem preservado e bordas recristalizadas a novos grãos. A granulometria é em torno de 0,2 mm e ocupa os interstícios entre os demais minerais. A biotita ocorre como lamelas subédricas, e sua granulometria não ultrapassa $0,8 \mathrm{~mm}$ na porção poliminerálica, porém nos níveis monominerálicos a biotita ocorre como agregados muito finos devido à recristalização. Segundo Yardley (1994), essa associação indica condições de fácies anfibolito de média à alta pressão. Epidoto, sericita, tremolita, clinozoisita, escapolita e calcita como produtos retrometamórficos indicam condições de fácies xisto verde. A substituição de plagioclásio por escapolita indica temperaturas inferiores a $625^{\circ} \mathrm{C}$, pressão em torno de $5 \mathrm{~kb}$ e que $\mathrm{CO}_{2}$ era um fluido presente (Aitken 1983).

Intrusões félsicas Foram distintos dois tipos de granitos pela textura e composição mineral: monzogranito e sienogranito.

Os monzogranitos são rochas equigranulares médias, hipidiomórficas, com índice de cor em média de $3 \%$, sendo classificados como hololeucocráticos. A mineralogia essencial é constituída por microclínio $(23,4 \%)$, plagioclásio $(32,1 \%)$, quartzo $(26,8 \%)$, biotita $(14,9 \%)$ e hornblenda (2,5\%). Os acessórios são opacos, titanita, zircão, sendo os secundários, sericita e clorita.

Nos monzogranitos, são observadas duas gerações de quartzo: a primeira, sob condições de pressão mais elevada, é representada por cristais arredondados inclusos nos feldspatos; a segunda, sob condições de pressão mais reduzida, é representada por cristais granulares xenomórficos, com dimensão média de 2,2 $\mathrm{mm}$ ocorrendo em agregados e/ou isolados. Normalmente, apresentam-se microfraturas, fraca extinção ondulante e inclusões de biotita, microclínio, titanita, zircão e opacos.

O plagioclásio ocorre como cristais tabulares, hipidiomórficos e xenomórficos de granulometria em média de 2,0 $\mathrm{mm}$. Apresenta-se levemente 
alterado para sericita e com poucas inclusões, sendo mais comuns: opacos, biotita e raro quartzo. $\mathrm{O}$ microclínio apresenta-se em cristais hipidiomórficos tabulares e, mais raramente, em xenomórficos, com dimensões médias de 2,4 $\mathrm{mm}$. Mostra inclusões de quartzo arredondado e, mais raras, de opacos, biotita e zircão. A biotita ocorre como lamelas hipidiomórficas medindo aproximadamente $1,8 \mathrm{~mm}$, isoladas ou em agregados. Encontram-se intensamente alteradas para clorita. A hornblenda apresenta-se como cristais anédricos, isolados, variando entre 0,8 a $1,7 \mathrm{~mm}$. A titanita varia de idiomórfica à xenomórfica, medindo de 0,2 a $1,5 \mathrm{~mm}$. Constitui grãos isolados, às vezes sendo substituídos por opacos. O zircão ocorre em cristais menores, sob um hábito prismático, com tamanho entre 0,1 a $0,3 \mathrm{~mm}$, inclusos no quartzo e no microclínio. Os minerais opacos ocorrem em cristais individualizados, xenomórficos e hipidiomórficos, disseminados ou inclusos em quartzo, microclínio e plagioclásio. Os produtos de alteração são sericita e clorita, formados às expensas de feldspato e biotita, respectivamente.

Os sienogranitos são caracterizados por gradação textural das bordas para o centro do corpo granítico e pela coloração rósea. Nas bordas, os mesmos apresentam uma textura equigranular, enquanto que no centro a textura é equigranular com tendência porfirítica. As rochas equigranulares possuem índice de cor (5\%), classificando-as como leucocrática. Sua mineralogia essencial consiste de quartzo, microclínio, plagioclásio e a fase máfica presente é biotita. Os acessórios são representados por titanita, zircão e opacos, tendo como secundários, a clorita e a sericita.

O quartzo $(27,2 \%)$ é anédrico, com dimensões médias de $2,0 \mathrm{~mm}$, ocorrendo como aglomerados monominerálicos e/ou em grãos isolados, intersticiais aos demais minerais. Possuem inclusões de titanita, zircão e opacos e exibem fraca extinção ondulante. O plagioclásio $(15,3 \%)$ ocorre em hábito tabular, subédrico, com dimensão média de 3,0 mm. Em alguns grãos verifica-se a formação de mirmequita no contato com microclínio, encontram-se levemente alterados para sericita. O microclínio $(46,5 \%)$ ocorre como cristais tabulares, subédricos a anédricos medindo cerca de 2,0 $\mathrm{mm}$. Possuem intercrescimentos pertíticos, inclusões de titanita e opacos e leve alteração para sericita. A biotita $(9,3 \%)$ ocorre como lamelas subédricas a anédricas com dimensão média de 2,0 mm, em grãos isolados ou em agregados, intensamente alterada para clorita. A titanita apresenta-se em cristais euédricos de $0,4 \mathrm{~mm}$, inclusa em quartzo e microclínio. A allanita apresenta-se em cristais prismáticos idiomórficos, zonados, com cerca de $2,4 \mathrm{~mm}$. O zircão é prismático, idiomórfico, submilimétrico, ocorrendo como inclusões em quartzo. Os opacos são predominantemente xenomórficos de hábito granular. Ocorrem como inclusões nas fases minerais principais, isolados e disseminados.

Quando porfirítica, a matriz é fina, composta por plagioclásio, microclínio, biotita e quartzo. Este apresenta-se formando aglomerados monominerálicos ou associados aos demais minerais. Os fenocristais são de microclínio, atingindo até $30,0 \mathrm{~mm}$.

\section{GEOQUÍMICA Foram analisados elemen-} tos maiores, pelo método de fluorescência de raios $\mathrm{X}$ (Instituto de Geociências da Universidade Federal do Rio de Janeiro - IGEO/UFRJ), e elementos traço e terras raras pelo método ICP-MS (Acme Laboratory, Canadá). Os resultados (Tabs. $1 \mathrm{a} 4$ ) foram monitorados por duplicação de amostras e análises previamente realizadas.

Metamáficas As rochas metamáficas são classificadas como basaltos a basaltos andesíticos (Fig. 3). No diagrama TAS (Cox et al. 1979), elas são projetadas na transição entre os campos das séries subalcalina e alcalina (Fig. 4), no entanto, a projeção no diagrama $\mathrm{Nb} / \mathrm{Y}$ versus $\mathrm{SiO}_{2}$ demonstra um caráter

Tabela 1 - Composição química dos elementos maiores nos granitoides estudados

\begin{tabular}{lcccccccccccc}
\hline Amostra & $\mathrm{SiO}_{2}$ & $\mathrm{TiO}_{2}$ & $\mathrm{Al}_{2} \mathrm{O}_{3}$ & $\mathrm{FeO}_{\mathrm{t}}$ & $\mathrm{MnO}$ & $\mathrm{MgO}$ & $\mathrm{CaO}$ & $\mathrm{Na}_{2} \mathrm{O}$ & $\mathrm{K}_{2} \mathrm{O}$ & $\mathrm{P}_{2} \mathrm{O}_{5}$ & $\mathrm{TOTAL}$ & $\mathrm{LOI}$ \\
\hline DCI03 & 72,92 & 0,19 & 14,28 & 1,45 & 0,05 & 0,18 & 0,97 & 3,13 & 6,11 & 0,03 & 99,72 & 0,41 \\
\hline DCI42 & 70,64 & 0,34 & 14,48 & 2,12 & 0,03 & 0,31 & 1,63 & 3,66 & 5,29 & 0,06 & 99,54 & 1,0 \\
\hline PCI02 & 72,07 & 0,30 & 14,29 & 2,34 & 0,04 & 0,26 & 1,26 & 3,26 & 5,58 & 0,06 & 100,39 & 0,90 \\
\hline DCI34 & 74,46 & 0,06 & 14,11 & 0,67 & 0,02 & 0,16 & 1,42 & 3,50 & 5,00 & 0,002 & 99,81 & 0,41 \\
\hline PCI14 & 73,41 & 0,1 & 14,53 & 0,95 & 0,03 & 0,18 & 1,22 & 3,25 & 5,68 & 0,03 & 99,95 & 0,58 \\
\hline DCI47 & 71,54 & 0,3 & 14,24 & 2,29 & 0,04 & 0,26 & 1,25 & 3,29 & 5,54 & 0,07 & 100,4 & 1,58 \\
\hline NCI21 & 72,65 & 0,45 & 14,34 & 2,26 & 0,03 & 0,39 & 1,28 & 3,54 & 3,92 & 0,08 & 100,18 & 1,24 \\
\hline DCI49 & 70,49 & 0,48 & 15,50 & 2,50 & 0,01 & 1,14 & 3,87 & 4,25 & 1,50 & 0,08 & 100,27 & 0,49 \\
\hline NCI19 & 70,98 & 0,30 & 15,42 & 2,06 & 0,02 & 0,99 & 3,42 & 5,12 & 1,21 & 0,09 & 100,69 & 1,08 \\
\hline NCI-20 & 74,74 & & 12,83 & 0,41 & & & 2,69 & 2,85 & 5,44 & & & \\
\hline
\end{tabular}




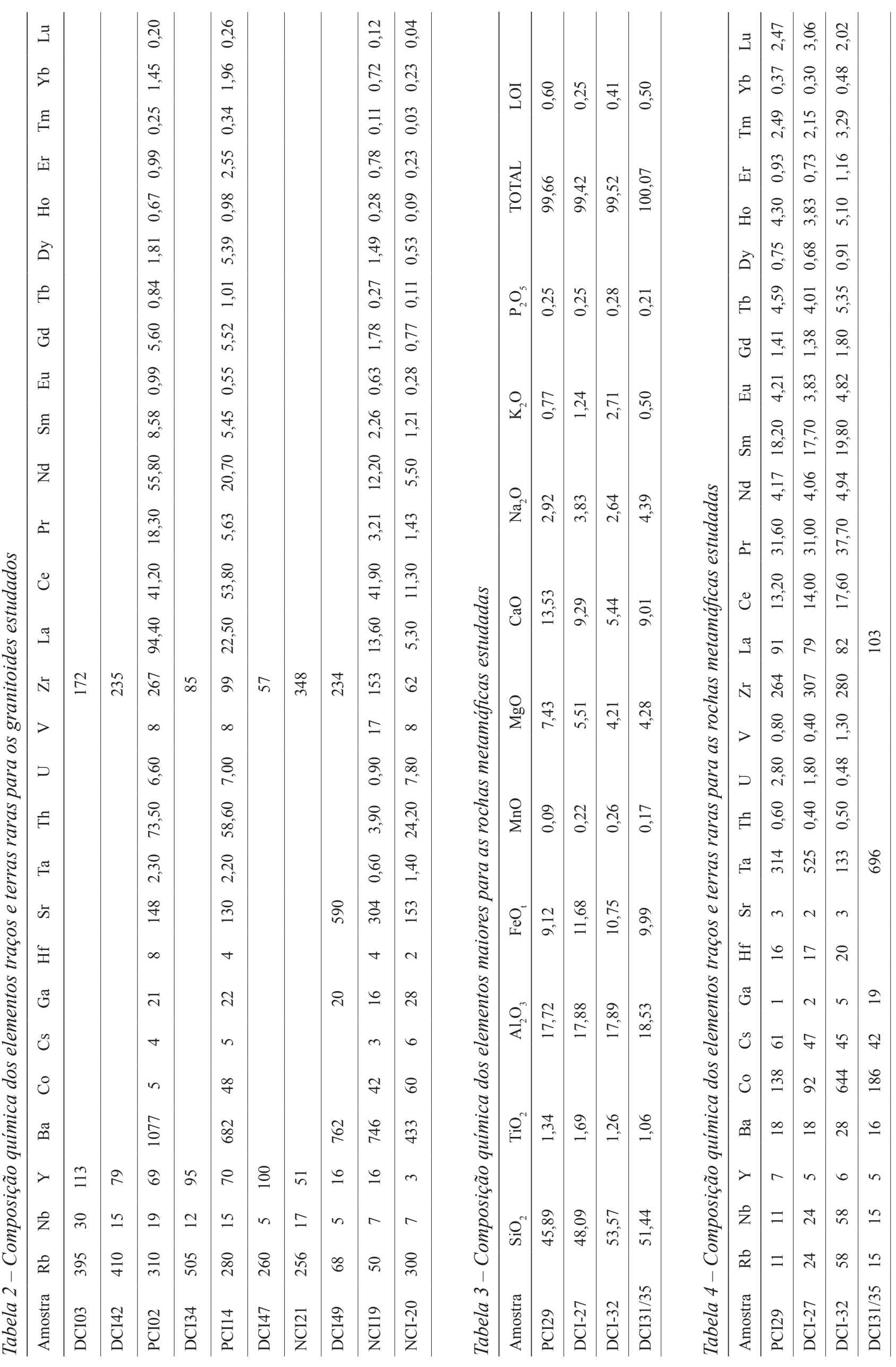


subalcalino (Fig. 5). Nos diagramas $\mathrm{SiO}_{2}$ versus $\mathrm{K}_{2} \mathrm{O}$ são projetadas nos campos da série cálcio-alcalina e cálcio-alcalina de alto-K e no diagrama AFM descrevem o trend das rochas cálcio-alcalinas (Figs. 6 e 7).

Os diagramas discriminantes de ambientes tectônicos sugerem ambiguidade nas ambiências (Figs. 8 a 10), com a maioria das amostras projetando-se no campo dos basaltos calcioalcalinos ou naqueles em que há sobreposição entre basaltos de arcos vulcânicos e basaltos intraplacas. Nestes diagramas, uma amostra (DCI-32) projeta-se nos campos onde

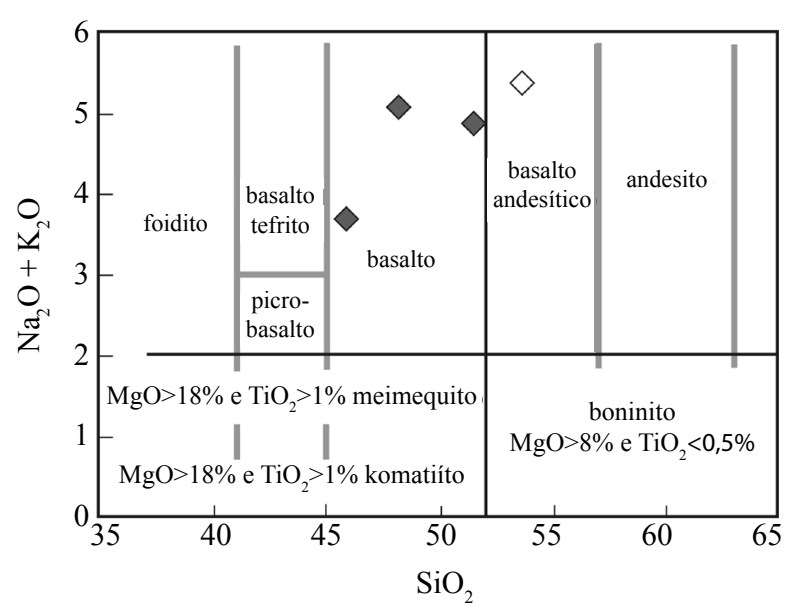

Figura 3 -Diagrama TAS (total álcalis - sílica) para classificação de rochas ultramáficas (Le Bas 2000), mostrando que as rochas metamáficas apresentam composição variando de basalto a basalto andesítico. Símbolos: $\diamond$ (metamáficas); (amostra DCI-32).

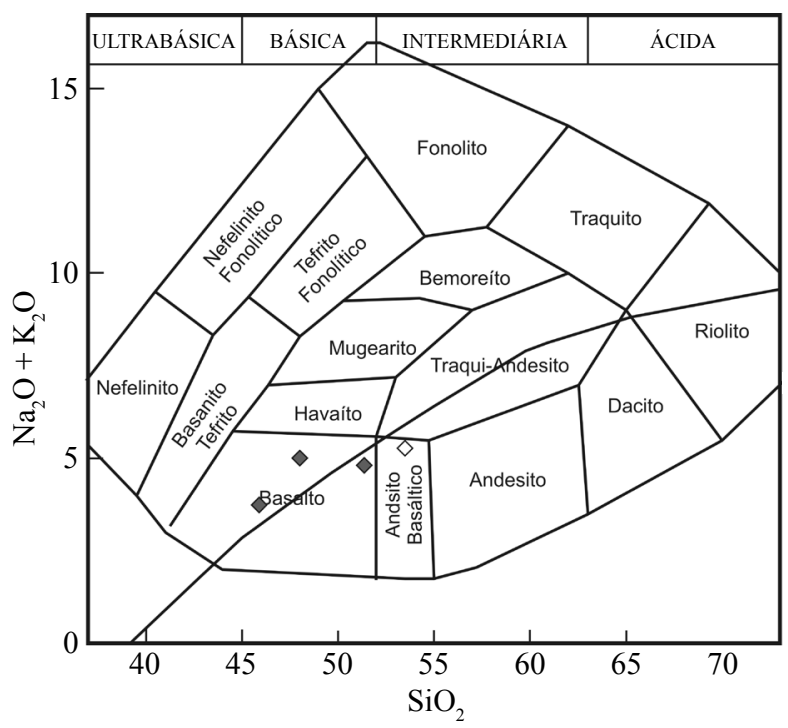

Figura 4-Diagrama TAS (Cox et al. 1979) mostrando que as rochas metamáficas projetam-se nos limites entre os campos das séries subalcalina e alcalina. Símbolos: $\diamond$ (metamáficas); (amostra DCI-32). se observa sobreposição entre os MORB, normal ou enriquecido, e os basaltos toleíticos intraplacas. Essa ambiguidade é comumente observada neste tipo de diagrama, de forma que eles não são os melhores indicadores de ambiência tectônica. Por esse motivo, alguns autores utilizam as razões de elementos traços, levando em consideração os diversos graus de fracionamento de tais elementos em condições distintas e a variação nos teores em fontes diferentes (Baker et al. 1977, Bougault \& Treuil 1980, Sun \& McDonough 1989).

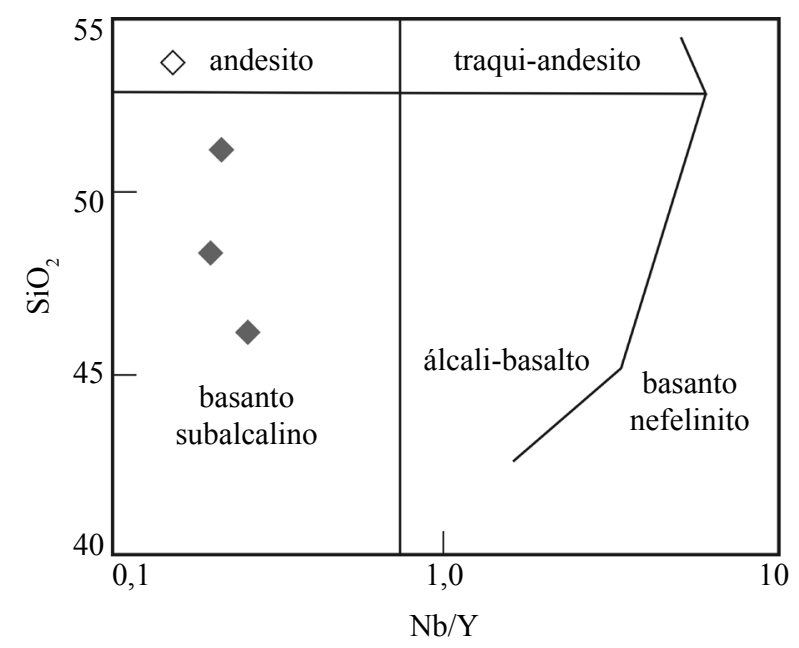

Figura 5-Diagrama Nb/Yx $\mathrm{SiO}_{2}$ (Winchester \& Floyd 1977) mostrando o caráter subalcalino das rochas metamáficas estudadas. Símbolos: $\diamond$ (metamáficas); - (amostra DCI-32).

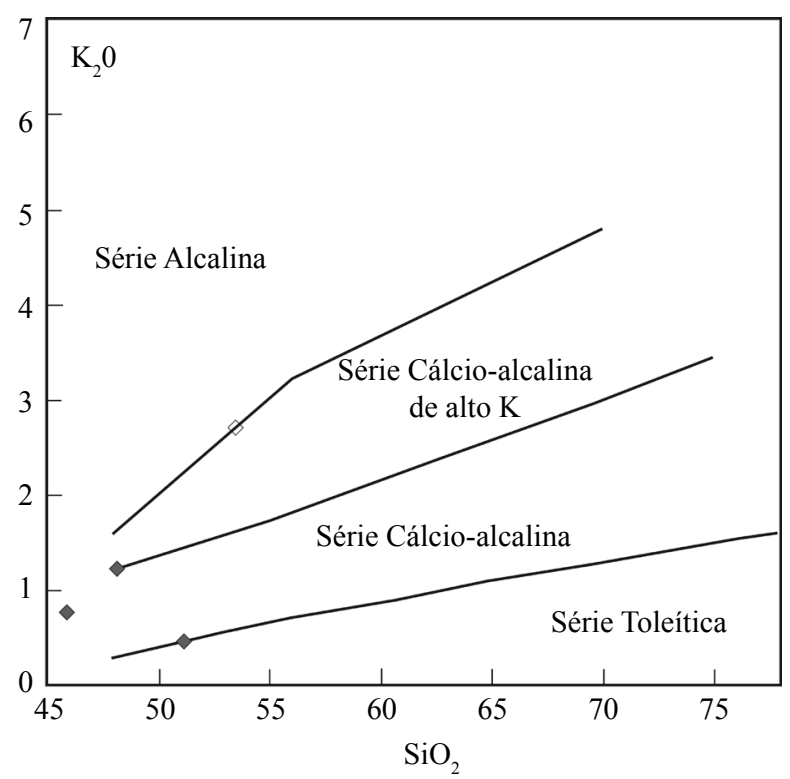

Figura 6 - Diagrama $\mathrm{SiO}_{2} \times \mathrm{K}_{2} \mathrm{O}$ (Pecerillo \& Taylor 1976) mostrando que as rochas metamáficas estudadas variam de cálcio-alcalinas a cálcio-alcalinas de alto-K. Simbolos: $\diamond$ (metamáficas); (amostra DCI-32). 
A utilização isolada da razão $\mathrm{Zr} / \mathrm{Nb}$ na distinção dos tipos de basaltos fornece uma sobreposição. De forma geral, considera-se que os MORB-N têm razões $\mathrm{Zr} / \mathrm{Nb}$ mais elevadas ( $>30$ ) do que os MORB-E $(4-25)$, MORB-T $(8-27)$, CFB $(10-16)$ e OIB

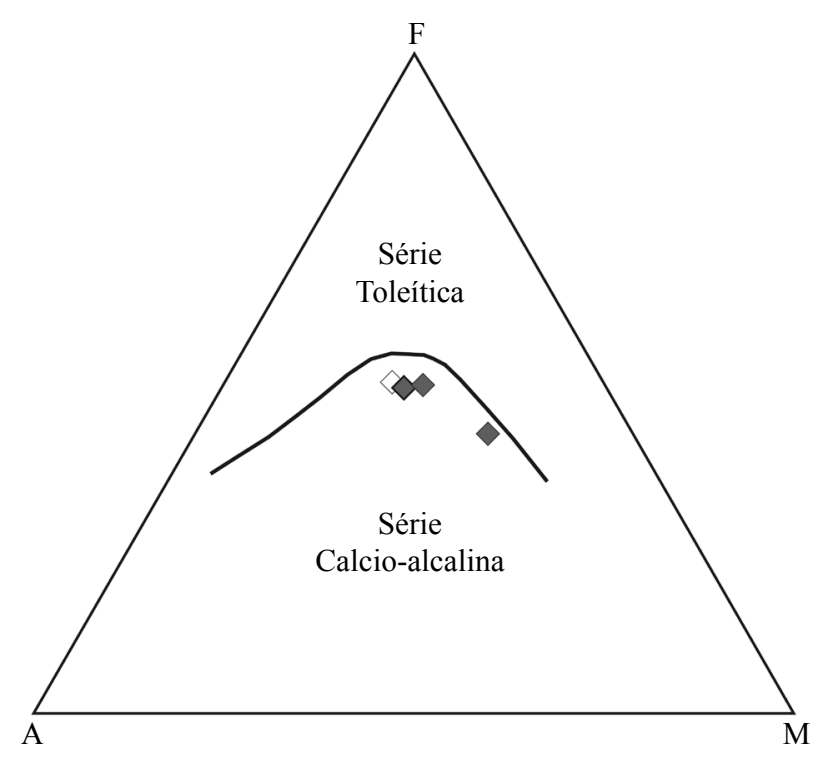

Figura 7 - Diagrama AFM $\left(\left(\mathrm{Na}_{2} \mathrm{O}+\mathrm{K}_{2} \mathrm{O}\right)-\mathrm{FeO}-\right.$ $\mathrm{MgO}$, incluindo a curva de Irvine \& Baragar 1971) mostrando que as rochas metamáficas estudadas projetam-se no campo da série cálcio-alcalina. Símbolos: $\diamond$ (metamáficas); (amostra DCI-32).

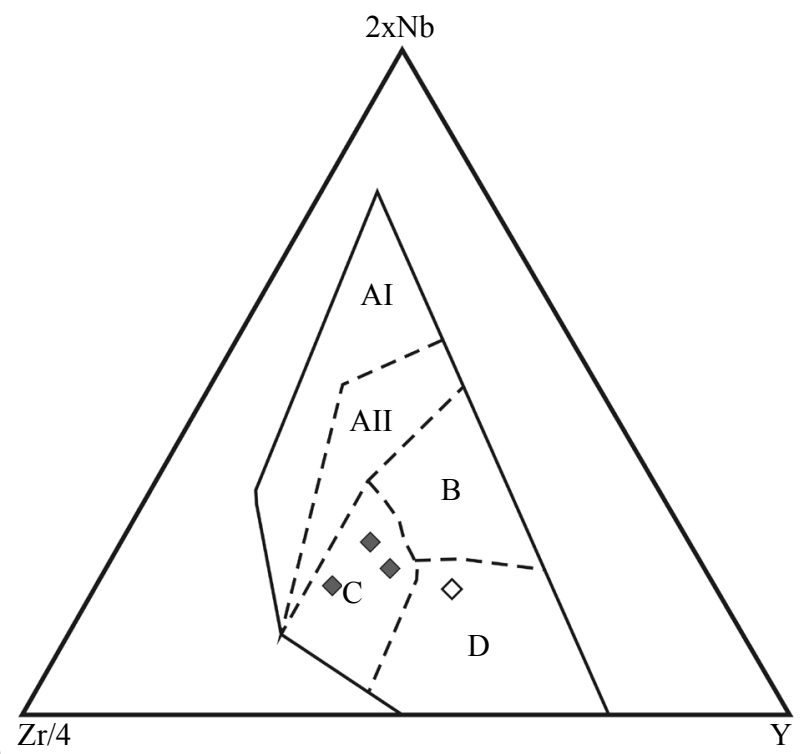

Figura 8 - Diagrama $\mathrm{Zr} / 4$ versus $2 x \mathrm{Nb}$ versus $Y$ (Meschede 1986) mostrando que as rochas metamáficas estudadas projetam-se, em sua maioria, no campo de toleitos intraplacas e de arco vulcânico. AI: basaltos alcalinos intraplacas; AII: basaltos alcalinos intraplacas e toleitos intraplacas; $C$ : toleitos intraplacas e basaltos de arco vulcânico; D: MORB-Ne basaltos de arcos vulcânicos. Símbolos: $\diamond$ (metamáficas); (amostra DCI-32).
$(8,45$ - 29,0), devido ao empobrecimento de $\mathrm{Nb}$ em relação aos outros elementos incompatíveis (Fitton et al. 1997). A utilização combinada com outros elementos de ligação forte de menor mobilidade permite uma melhor distinção, como visto nos diagramas $\mathrm{Zr} / \mathrm{Y}$ versus $\mathrm{Nb} / \mathrm{Y}$ e Nb/Th versus $\mathrm{Zr} / \mathrm{Nb}$ (Fig. 11). Nestes, as rochas metamáficas estudadas projetam-se, em sua maioria, no campo dos arcos vulcânicos, próximas às assinaturas de um componente enriquecido associado à crosta continental superior e à litosfera subcontinental, sem influência de plumas mantélicas. Entretanto, a amostra DCI-32 projeta-se no campo dos basaltos associados a fontes com plumas mantélicas, próximo ao componente manto primitivo.

As rochas estudadas apresentam razões $\mathrm{Zr}$ / $\mathrm{Nb}$ variando entre 12,6 a 20,6, valores também observados em basaltos calcio-alcalinos colisionais $(5,0-25,0)$ e nos MORB-E e -T. Porém, distinguemse destes últimos pelas menores razões $\mathrm{Nb} / \mathrm{Th}$ e $\mathrm{Nb} / \mathrm{Y}$ (Fig. 11), à exceção da amostra DCI-32.

As razões médias citadas foram compiladas de Fodor \& Veter (1984), Humphris et al. (1985), Picard et al. (1995), Fitton et al. (1997), Modeland et al. (2003), Condie (2005), Wang et al. (2005), Kay et al. (2007), Bouvier et al. (2010) e Geokem (página visitada em 19/04/2011).

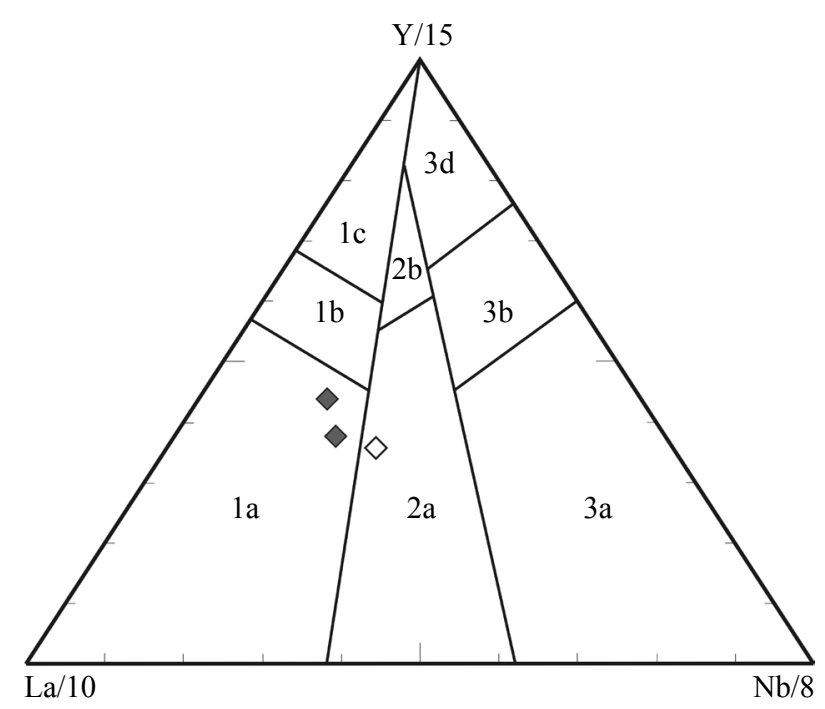

Figura 9 - Diagrama La/10 versus $Y / 15$ versus $\mathrm{Nb} / 8$ (Cabanis \& Lecolle 1989) mostrando que as rochas metamáficas estudadas projetam-se na transição entre os basaltos continentais e calcio-alcalinos. 1a: basaltos calcio-alcalinos; 1b: sobreposição entre as áreas 1a e 1c; 2a: basaltos continentais; $2 b$ : basaltos de bacias back-arc; 3a: basaltos alcalinos de rifts continentais; $3 b$ e 3c: MORB-E; 3d: MORB-N. Símbolos: $\diamond$ (metamáficas); (amostra DCI-32). 

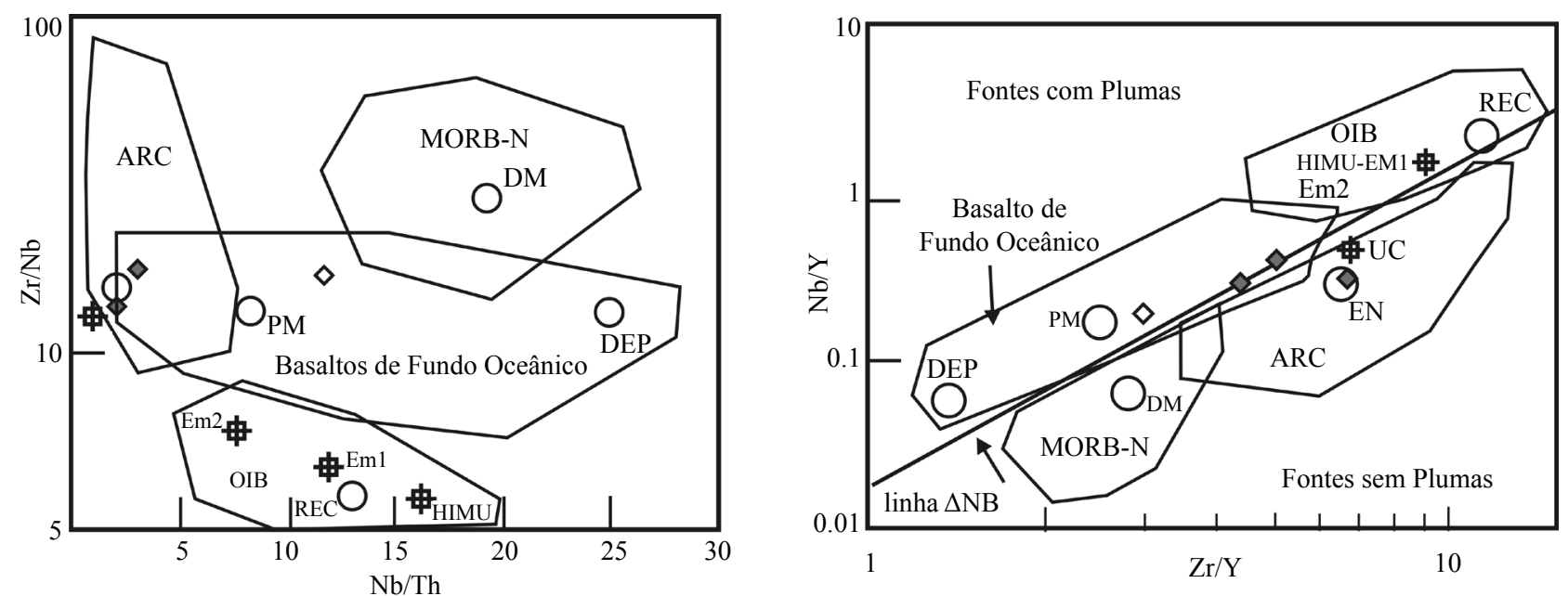

Figura 10 - Diagrama Th versus Zr/17 versus Nb/10 (Wood et al. 1979) mostrando que as rochas metamáficas estudadas projetam-se no campo dos basaltos calcio-alcalinos e no de sobreposição MORB-E/WPT. IAT: basaltos toleiticos de arco de ilhas; CAB: basaltos calcio-alcalinos; WPT: basaltos toleiticos intraplacas; WPA: basaltos alcalinos intraplacas. Símbolos: $\diamond$ (metamáficas); (amostra DCI-32).

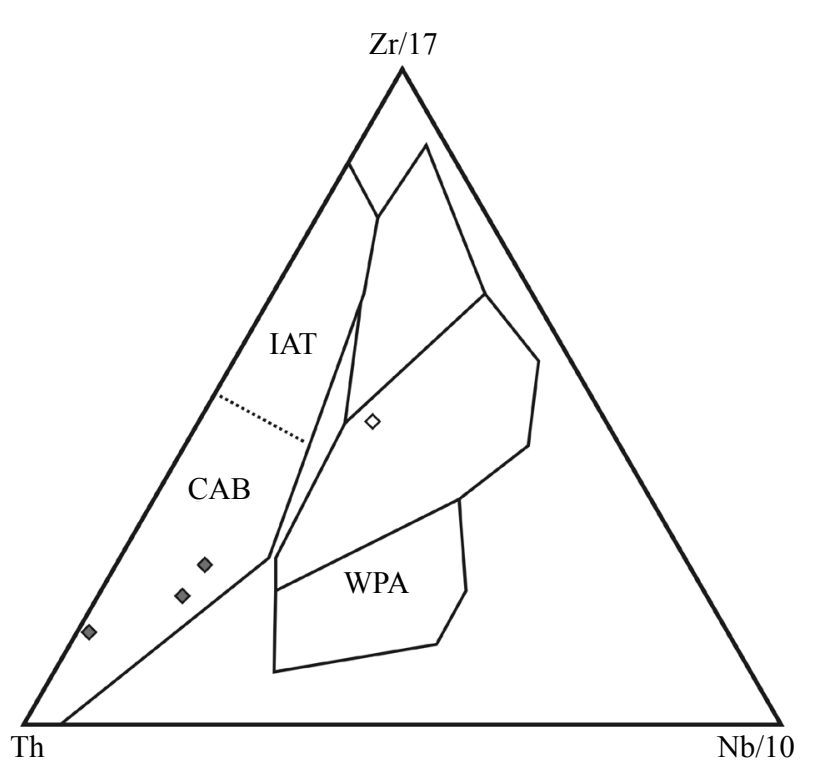

Figura 11 - Diagramas $\mathrm{Zr} / \mathrm{Y}$ versus $\mathrm{Nb} / \mathrm{Y}$ e $\mathrm{Nb} /$ Th versus $\mathrm{Zr} / \mathrm{Nb}$ (Condie 2005) mostrando que as rochas metamáficas estudadas têm afinidades com basaltos de arcos. PM: manto primitivo; DM: manto empobrecido superior; HIMU: fontes com elevadas razões U/Pb, Em1 e Em2 - fontes mantélicas enriquecidas; ARC: basaltos relacionados a arcos; MORB-N: basaltos de dorsais mesoceânicas; OIB: basaltos de ilhas oceânicas; DEP: manto empobrecidoprofundo; EM: componenteenriquecido; REC: componente reciclado; SUB: subducção; $\triangle N b$ : expressa a abundância ou o excesso de $N b$. Simbolos: $\diamond$ (metamáficas); (amostra DCI-32).
Utilizando os valores normalizados por Pearce (1996), verifica-se que a maioria dessas rochas é enriquecida nos elementos traços incompatíveis em relação aos MORB-N e -E, apresentando padrões fracionados com médias a elevadas razões LILE/HFSE (18,3 - 49,3), depressões $\mathrm{Ta}-\mathrm{Nb}$ e picos em Ce, feições típicas de basaltos calcio-alcalinos colisionais e toleítos intraplacas continentais (Figs. 12). A amostra DCI-32, que apresenta assinatura de um componente enriquecido do tipo manto primitivo, quando os valores são normalizados, apresenta padrão semelhante às demais, embora, observa-se teores anômalos dos LILE ( $\mathrm{K}, \mathrm{Rb}$ e Ba), provavelmente em decorrência da percolação de fluidos durante a intrusão dos granitos. Isso é evidenciado pela intensa flogopitização de tremolitas metamáficas.

Os padrões de elementos terras raras (ETR) (Fig. 13) mostram enriquecimento no amplo espectro desses elementos e ausência de anomalia de Eu. Contudo, um maior enriquecimento nos ETRL é evidenciado pelas moderadas razões ETRL e ETRP $\left(\mathrm{Ce}_{\mathrm{N}} / \mathrm{Yb}_{\mathrm{N}}=2,5-4,8\right)$. Feições essas, características das associações cálcio-alcalinas. Nos toleítos intraplacas continentais, as razões $\mathrm{Ce} / \mathrm{Yb}$ apresentam um maior intervalo de variação, com 6,5 a 21,2 (Sengupta \& Ray 2010, Basaltic Volcanism Study Project 1981).

Granitos Os resultados analíticos indicam que as duas fácies petrográficas reconhecidas apresentam diferentes assinaturas químicas. 

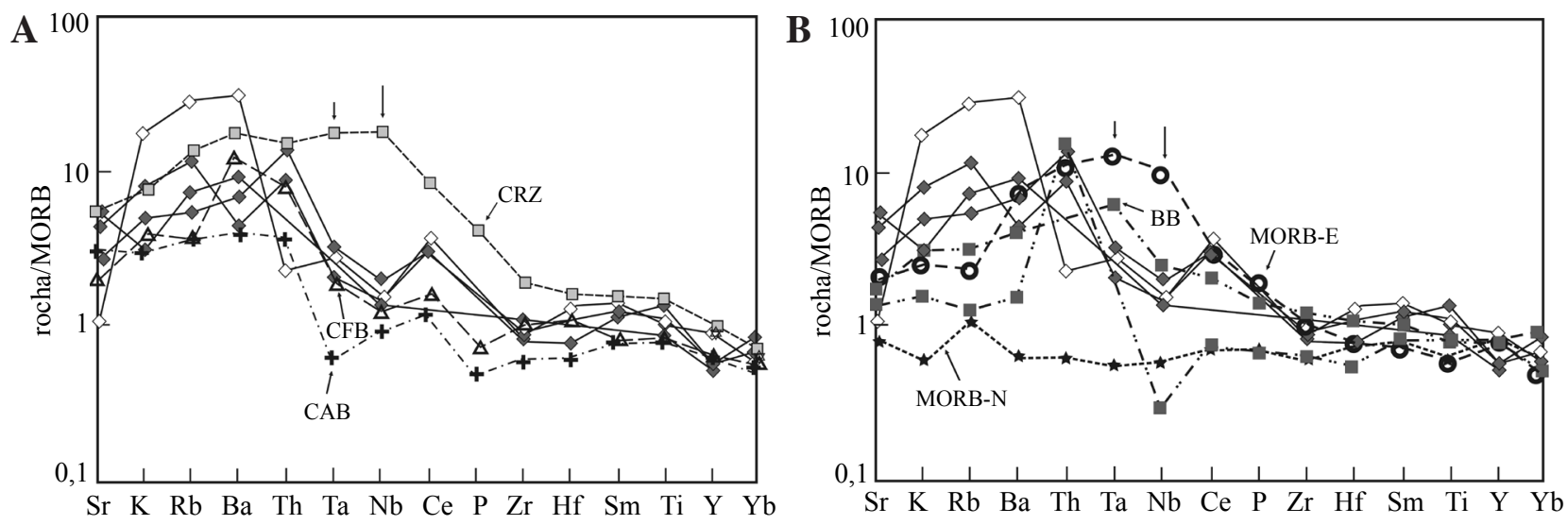

Figura 12 - (A): Spidergrams mostrando que as rochas metamáficas estudadas assemelham-se aos basaltos calcioalcalinos. No diagrama encontram-se também projetados os padrões para os basaltos calcio-alcalinos (+CAB,

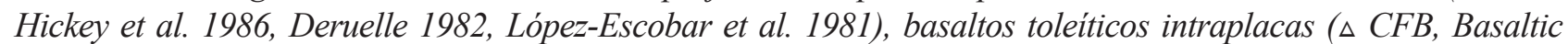
Volcanism Study Project, 1981), basaltos alcalinos intraplacas (- CRZ, Basaltic Volcanism Study Project, 1981). (B): basaltos empobrecidos de dorsais mesoceânicas ( $\star$ MORB-N, Schilling et al. 1983) e basaltos enriquecidos de dorsais mesoceânicas (口 MORB-E, Basaltic Volcanism Study Project, 1981) e basaltos calcio-alcalinos de bacia back-arc (ロ, BB, Sinton et al. 2003) para comparação. Os valores de normalização são os de Pearce (1996).

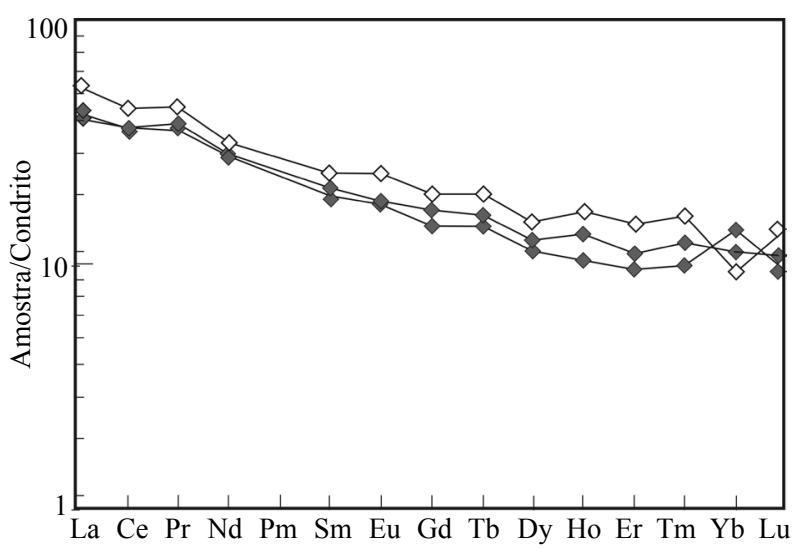

Figura 13 - Padrão normalizado de ETR para as rochas metamáficas estudadas. Valores de normalização são de Nakamura (1974). Símbolos: $\diamond$ (metamáficas); (amostra DCI-32).

Os monzogranitos apresentam grande variação química, registrando-se altos teores de $\mathrm{SiO}_{2}$ $(70,5-72,7)$, baixos a elevados de $\mathrm{K}_{2} \mathrm{O}(1,1-4,0)$, moderados a elevados de $\mathrm{Na}_{2} \mathrm{O}(2,9-5,1)$ e moderadas a altas razões $\mathrm{FeO}_{\mathrm{t}} / \mathrm{FeO}_{\mathrm{t}}+\mathrm{MgO}(0,68-0,80)$.

Nos diagramas de Harker, à exceção do $\mathrm{K}_{2} \mathrm{O}$, com relação aos monzogranitos, os elementos maiores apresentam trends negativos (Fig. 14). Nos diagramas $\mathrm{SiO}_{2}$ versus $\mathrm{K}_{2} \mathrm{O}$ e AFM (Figs. 15 e 16), projetamse no campo da série cálcio-alcalina à cálcio-alcalina de alto- $\mathrm{K}$ e nos diagramas $\mathrm{SiO}_{2}$ x $\mathrm{FeO} /(\mathrm{FeO}+\mathrm{MgO})$ e $\mathrm{SiO}_{2} \times \mathrm{K}_{2} \mathrm{O}+\mathrm{Na}_{2} \mathrm{O}-\mathrm{CaO}$ (Frost et al. 2001; Figs. 17 e 18) projetam-se no campo dos granitos magnesianos e calcio-alcalinos. São metaluminosos, segundo o índice de Shand (Fig. 19). Os spidergrams mostram que os monzogranitos são mais empobrecidos nos elementos incompatíveis do que os sienogranitos, apresentando-se, porém, enriquecidos nos LILE com elevadas razões LILE/HFSE (27,5), picos suaves em $\mathrm{Ba}, \mathrm{K}$ e $\mathrm{Zr}$ e suaves depressões em $\mathrm{Nb}$ e $\mathrm{P}$ (Fig. 20). Nos diagramas discriminantes de ambiência tectônica, os monzogranitos mostram uma tendência com os ambientes colisionais (Figs. 21 e 22). Os padrões de ETR mostram que os monzogranitos são também empobrecidos nos ETR quando comparados aos sienogranitos (Fig. 23), com maiores razões ETRL/ETRP $(\mathrm{CeN} / \mathrm{YbN}=14,8)$ e ausência de anomalia de $\mathrm{Eu}$, compatível com os padrões da série cálcio-alcalina.

Os sienogranitos apresentam elevados teores de $\mathrm{SiO}_{2}(71,5-74,5), \mathrm{Na}_{2} \mathrm{O}(3,1-3,7), \mathrm{K}_{2} \mathrm{O}$ $(5,0-6,1), \mathrm{Ga}(20,7-26,0)$ e elevadas razões $\mathrm{FeO}_{\mathrm{t}} /$ $\left(\mathrm{FeO}_{\mathrm{t}}+\mathrm{MgO}\right)(0,81-0,90)$. Nos diagramas de Harker, apresentam trends com pontos de inflexão sugerindo que a cristalização fracionada pode ter sido um processo importante na sua evolução (Fig. 14). Nos diagramas para $\mathrm{FeO}_{\mathrm{t}}, \mathrm{TiO}_{2}$ e $\mathrm{P}_{2} \mathrm{O}_{5}$ a $\mathrm{SiO}_{2}$, o ponto de inflexão é em torno de $72 \%$, indicando extração de apatita e óxidos de $\mathrm{Fe}$-Ti a partir dessa composição. Nos diagramas para $\mathrm{Al}_{2} \mathrm{O}_{3}, \mathrm{CaO}$ e $\mathrm{Na}_{2} \mathrm{O}$, a inflexão fica em torno de $73 \%$ de $\mathrm{SiO}_{2}$, sugerindo que a cristalização de feldspato foi mais tardia. No diagrama $\mathrm{SiO}_{2}$ versus $\mathrm{K}_{2} \mathrm{O}$, projetam-se além da linha que delimita os campos alto-K e alcalino e no diagrama 

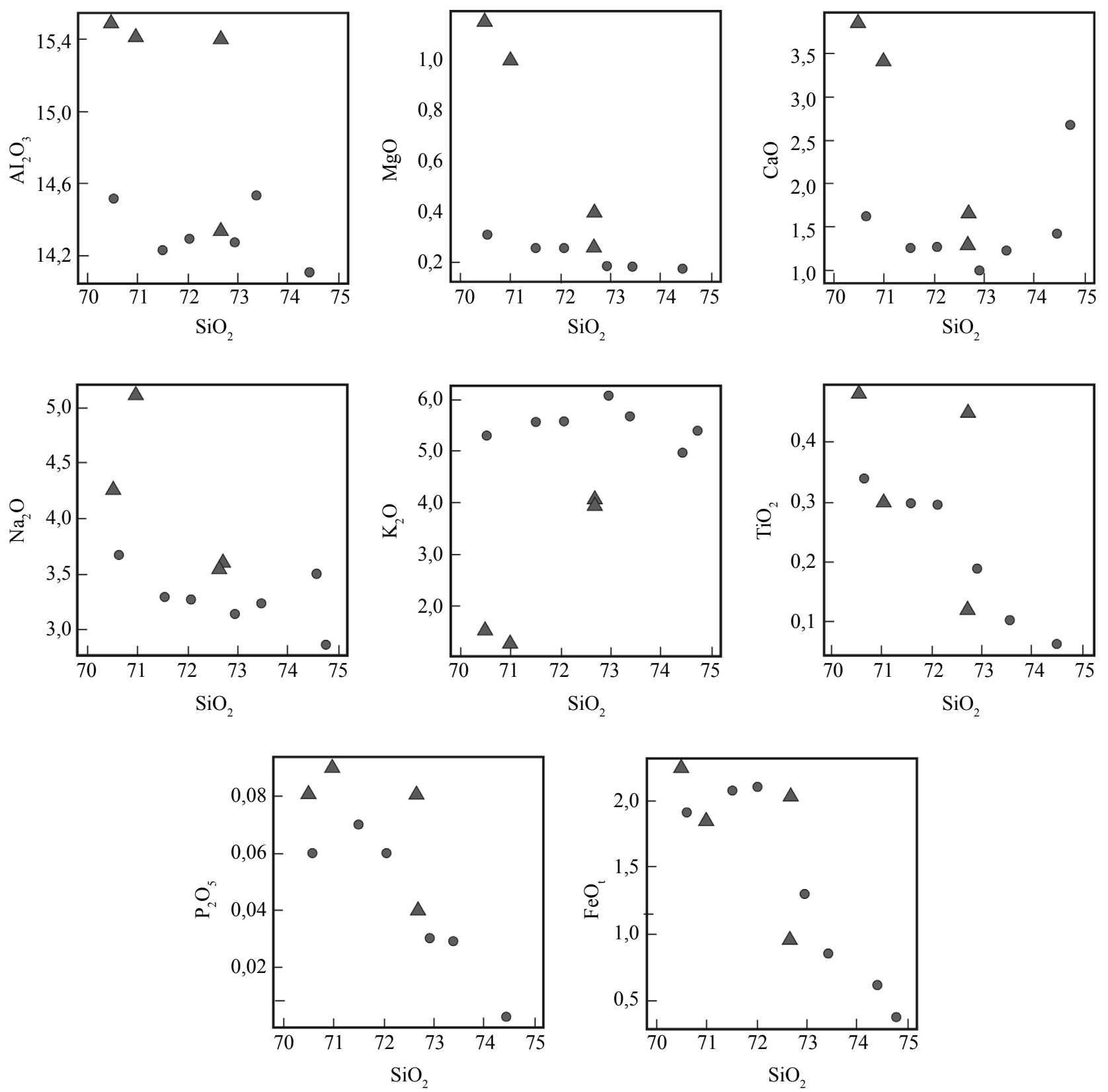

Figura 14 - Diagramas de Harker para os elementos maiores nos granitoides estudados. Símbolos: - (sienogranito); $\mathbf{\Delta}$ (monzogranito).

AFM descrevem, em sua maioria, o trend das rochas alcalinas (Figs. 15 e 16). Nos diagramas $\mathrm{SiO}_{2}$ x FeO/ $(\mathrm{FeO}+\mathrm{MgO})$ e $\mathrm{SiO}_{2} \times \mathrm{K}_{2} \mathrm{O}+\mathrm{Na}_{2} \mathrm{O}-\mathrm{CaO}$ (Frost et al. 2001), projetam-se no campo dos granitos ferrosos e alcalinos (Figs. 17 e 18). Segundo o índice de Shand, variam de peraluminosos a levemente peraluminosos (Fig. 19). Nos diagramas discriminantes de ambientes tectônicos, projetam-se no campo dos granitos alcalinos intraplacas (Figs. 22 e 23).

Os padrões de ETR (Fig. 21) mostram o enriquecimento desses elementos. São levemente fracionados $\left(\mathrm{Ce}_{\mathrm{N}} / \mathrm{Yb}_{\mathrm{N}}=7,0-7,3\right)$ com moderadas anomalias negativas de Eu $(0,3$ - 0,4), que, associadas às depressões em $\mathrm{Ti}, \mathrm{Sr}$ e às razões $\mathrm{FeO}_{\mathrm{t}}$ $\left(\mathrm{FeO}_{\mathrm{t}}+\mathrm{MgO}\right)(0,81-0,90)$, sugerem que a contribuição de fontes enriquecidas oxidantes (Fig. 24), com retenção de feldspato durante fusão parcial, podem ter contribuído para a gênese dessas rochas (Anderson 1983, Dall'Agnol et al. 2005).

DISCUSSÃO E CONCLUSÕES

A assinatura das rochas estudadas aponta para diversas fases de magmatismos básico e félsico associados ao Grupo Paraíba do Sul. 
No que se refere às rochas metamáficas, os dados apresentados apontam que os protólitos poderiam ter sido originados por diferentes fontes: uma fonte associada a arcos vulcânicos com um componente enriquecido associado à crosta continental superior e à litosfera subcontinental, sem influência de plumas mantélicas e um componente enriquecido do tipo manto primitivo. Santos Marins \& Duarte (2000) identificaram dois grupos de anfibolitos

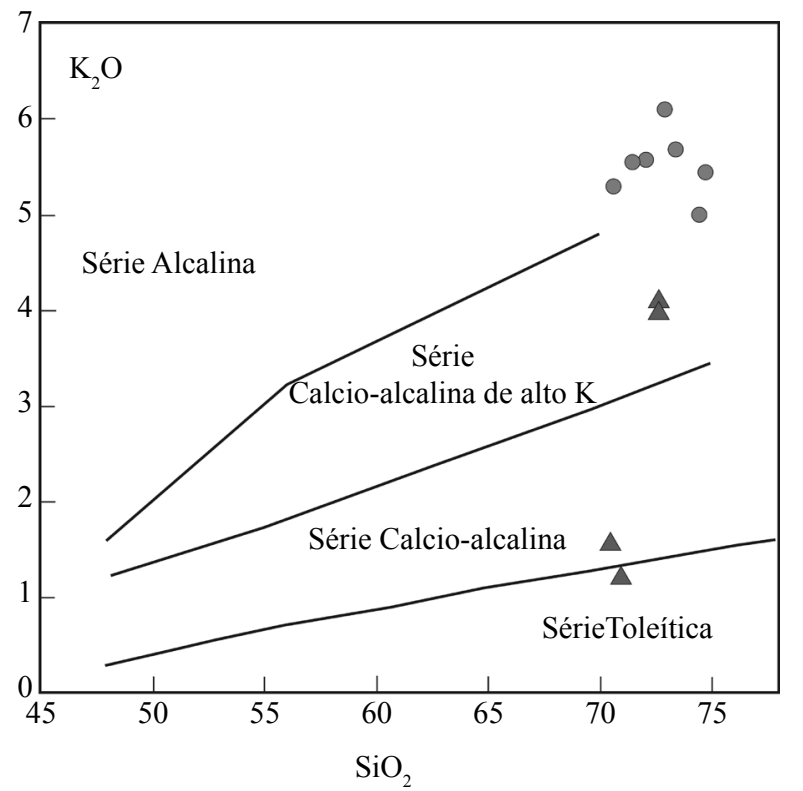

Figura 15 - Diagrama $\mathrm{SiO}_{2}$ versus $\mathrm{K}_{2} \mathrm{O}$ (Pecerillo \& Taylor 1976) mostrando que os granitos estudados pertencem a mais de uma série magmática. Símbolos:

- (sienogranito); $\mathbf{\Delta}$ (monzogranito).

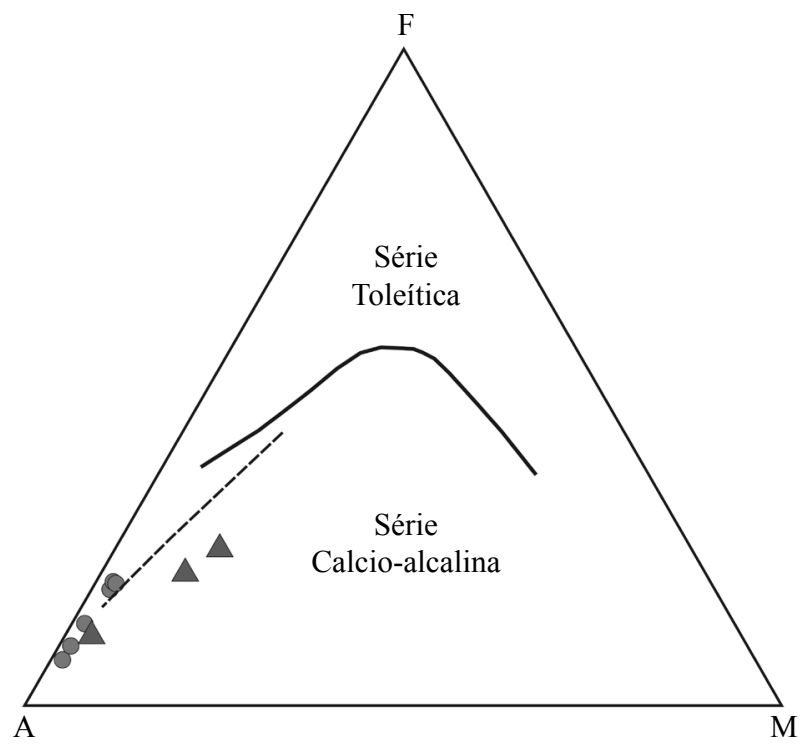

Figura 16 - Diagrama AFM $\left(\left(\mathrm{Na}_{2} \mathrm{O}+\mathrm{K}_{2} \mathrm{O}\right)-\mathrm{FeO}\right.$ - MgO, incluindo a curva de Irvine \& Baragar 1971) mostrando que os granitoides estudados variam de calcioalcalinos a alcalinos. Símbolos:

- (sienogranito); $\mathbf{\Delta}$ (monzogranito).

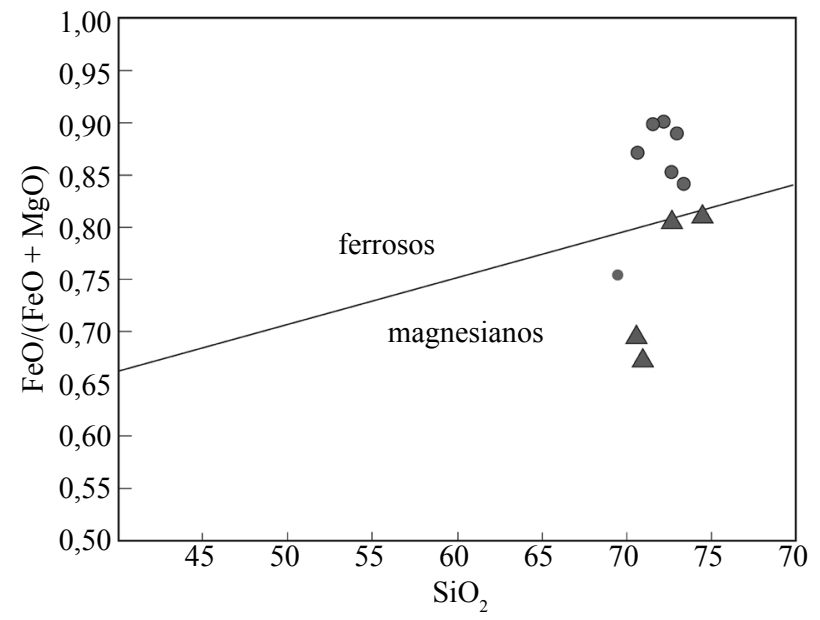

Figura 17 - Diagrama $\mathrm{SiO}_{2}$ versus $\mathrm{FeO} /(\mathrm{FeO}+\mathrm{MgO})$ mostrando que os granitoides calcio-alcalinos classificamse como magnesianos e os granitoides alcalinos como ferrosos. Símbolos: • (sienogranito); $\boldsymbol{\Delta}$ (monzogranito).

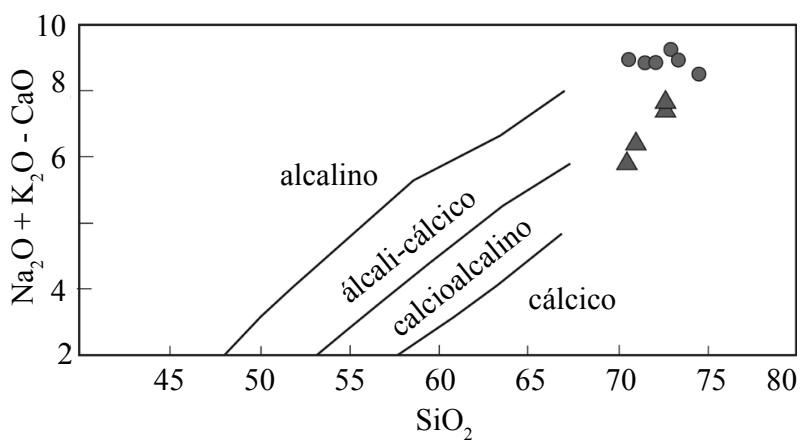

Figura 18 - Diagrama $\mathrm{SiO}_{2}$ versus $\left(\mathrm{Na}_{2} \mathrm{O}+\mathrm{K}_{2} \mathrm{O}\right.$ - CaO) mostrando que os granitoides estudados classificam-se como calcio-alcalinos e alcalinos. Símbolos: • (sienogranito); $\Delta$ (monzogranito).

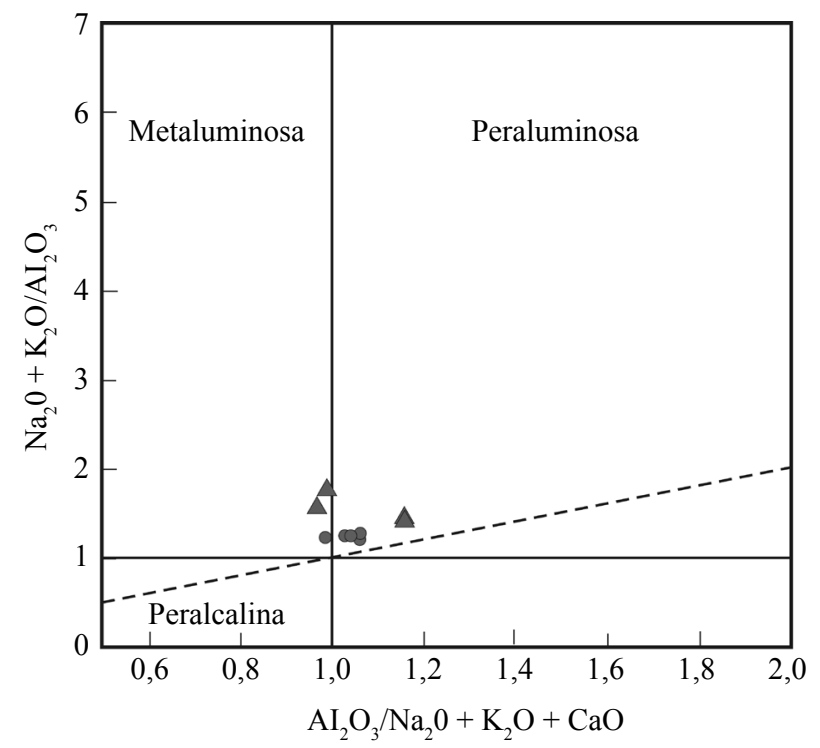

Figura 19 - Diagrama de Shand mostrando que os granitoides estudados variam de peraluminosos a levemente metaluminosos. Símbolos:

- (sienogranito); $\boldsymbol{\Delta}$ (monzogranito). 


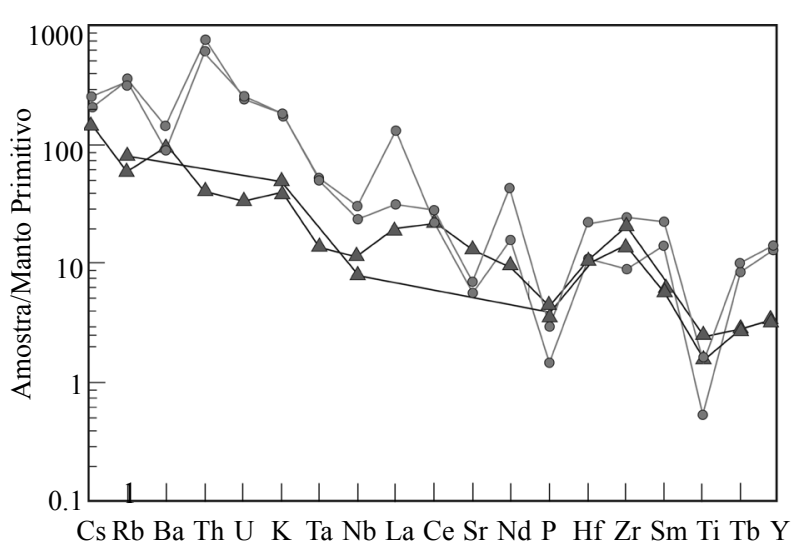

Figura 20 - Spidergram normalizado para o manto primitivo(Woodetal. 1979) paraos granitos estudados. Símbolos: • (sienogranito); $\boldsymbol{\Delta}$ (monzogranito).

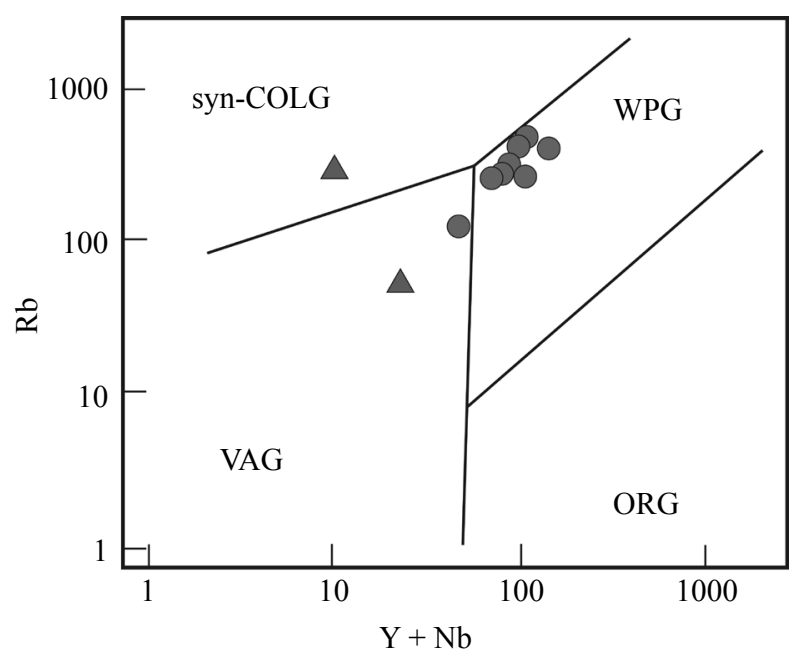

Figura 21 - Diagrama $Y+N b$ versus $R b$ (Pearce et al. 1984) sugerindo a ambiência tectônica dos granitos estudados. Símbolos: - (sienogranito); $\Delta$ (monzogranito).

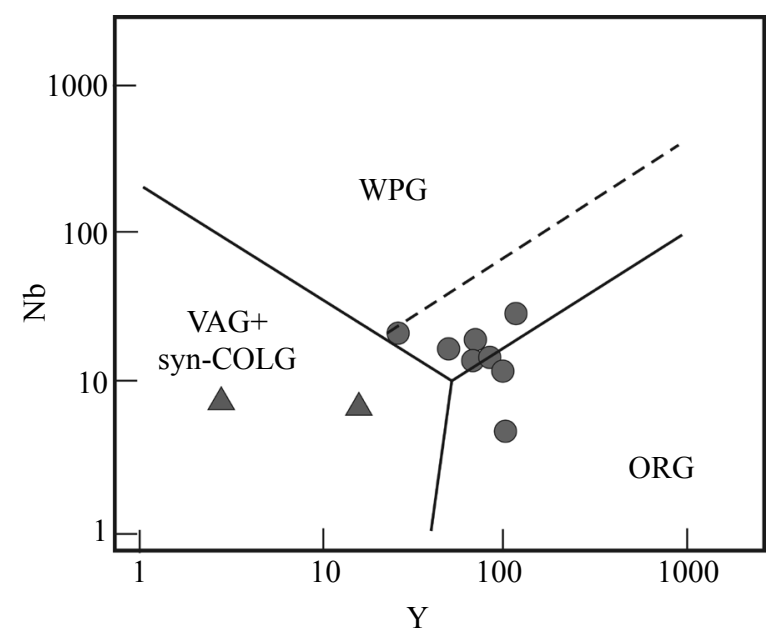

Figura 22 - Diagrama Y versus Nb (Pearce et al. 1984) sugerindo a ambiência tectônica dos granitos estudados. Símbolos: • (sienogranito); $\boldsymbol{\Delta}$ (monzogranito). no GPS: um maior, constituído por basaltos de derrames continentais e um de basaltos do tipo MORB-E.

Como o Grupo Paraíba do Sul compreende uma sequência marinha (Vieira 1977), é mais plausível que o magmatismo básico a ele relacionado também esteja associado a ambientes oceânicos. Ademais, o seu posicionamento Neoproterozoico e o fato de que as metamáficas foram submetidas a intenso metamorfismo e deformação, apresentando padrões de dobramentos semelhantes aos dos mármores encaixantes, indicam que as metamáficas foram

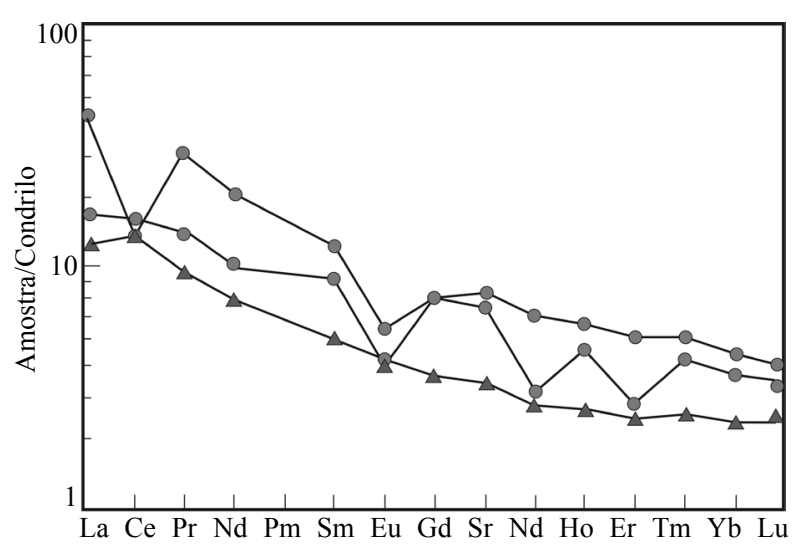

Figura 23 - Padrão normalizado de ETR para os granitos estudados. Os valores de normalização são do condrito de Nakamura (1974). Símbolos: - (sienogranito); $\mathbf{\Delta}$ (monzogranito).

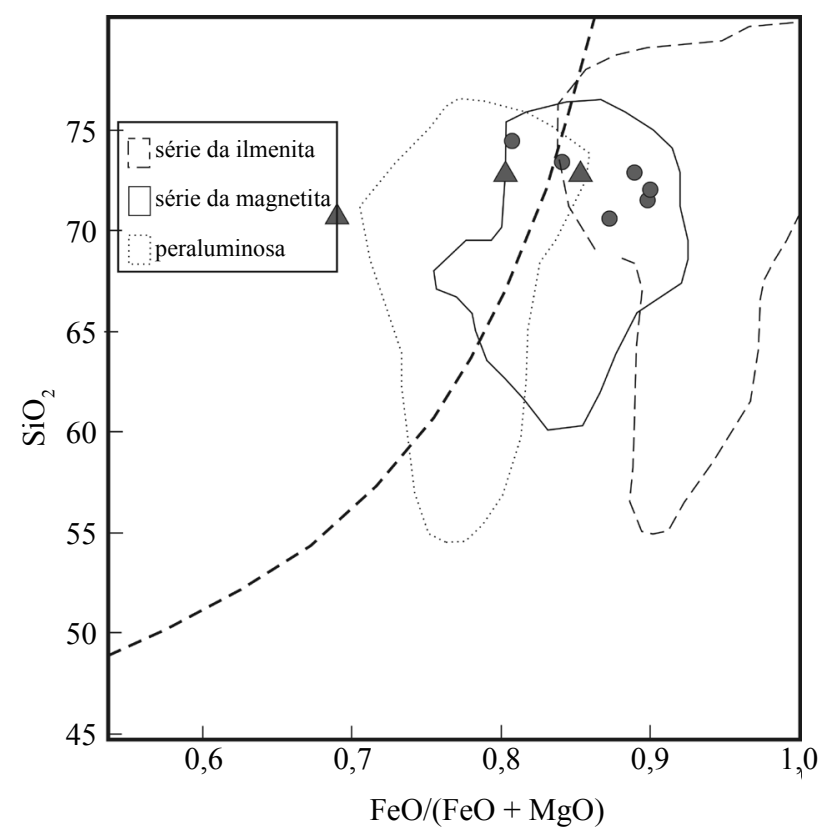

Figura 24 - Diagrama $\mathrm{FeO} /\left(\mathrm{FeO}_{t}+\mathrm{MgO}\right)$ versus $\mathrm{SiO}_{2}$ (Anderson 1980) mostrando que os granitos estudados pertencem, em sua maioria, à série da magnetita, refletindo condições mais oxidantes. Símbolos: • (sienogranito); $\boldsymbol{\Delta}$ (monzogranito). 


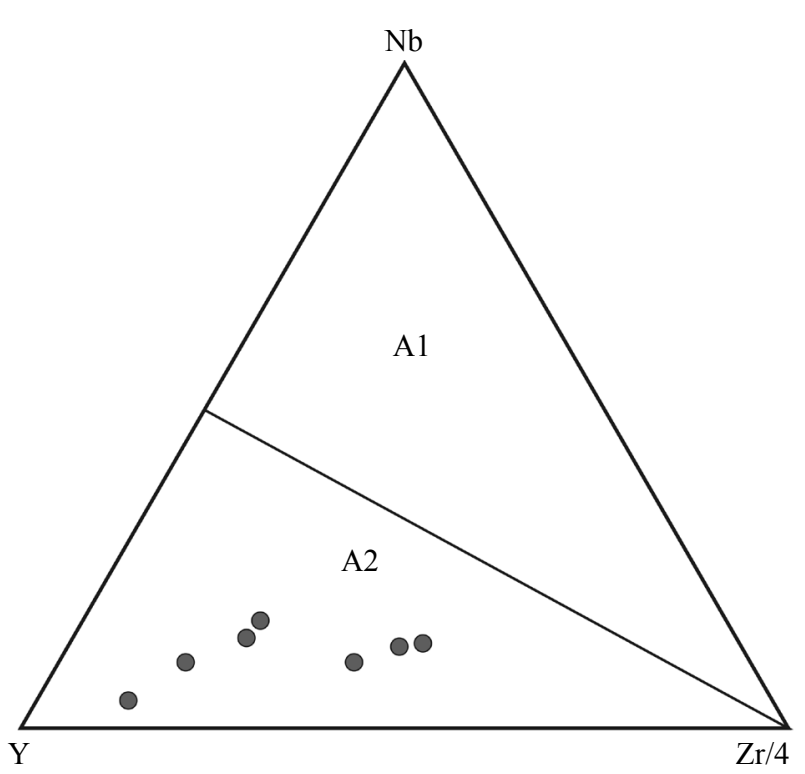

Figura 25 - Diagrama de Eby (1990) mostrando que os sienogranitos estudados são semelhantes aos granitos alcalinos pós-colisionais.

alojadas pré-deformação, e todo o conjunto foi deformado durante a compressão sin-Brasiliana.

Alguma ambiguidade entre a assinatura cálcio-alcalina e de derrames continentais vem do fato de ambos os reservatórios estarem associados a processos de reciclagem do manto e à intensa contaminação crustal, gerando líquidos enriquecidos em elementos incompatíveis e empobrecidos em Nb. Contudo, as incertezas estratigráficas não permitem maiores precisões acerca da origem dessas rochas.

Os monzogranitos apresentando assinatura variando de cálcio-alcalina à cálcio-alcalina de alto-K e os sienogranitos apresentando assinatura alcalina sugerem transição de regime tectônico e estágio orogenético. Eventos pós-colisionais iniciam-se com processos magmáticos ainda influenciados pelos materiais subductados e suítes predominantemente cálcio-alcalinas passando de normal para alto-K, enquanto que o final deste evento é caracterizado pelo alojamento de suítes alcalinas pós-orogênicas (Bonin et al. 1998). Além disso, abundante magmatismo calcioalcalino de alto-K é tipicamente pós-colisional e, frequentemente, ocorre associado a magmatismo shoshonítico ou alcalino/peralcalino marcando o final de uma orogênese (Sylvester 1989, Ligéois et al. 1998).

Os granitos alcalinos associados a ambientes distensivos pós-colisionais alojam-se sob o regime tectônico transicional dúctil-rúptil, mostrando um padrão estrutural típico (Sylvester 1989, Anderson 1980).

Feições que marcam a transição entre regimes dúctil-rúptil foram observadas na região estudada: granitos incipientemente deformados; intrusão dos granitos e pegmatitos em falhas transcorrentes semiconcordantes a discordantes com a foliação do mármore, representando as últimas estruturas registradas na área; intrusão de granitos cortando diques de metamáficas; zonas de cisalhamento dúcteis-rúpteis e fissuras de extensão sigmoidais, preenchidas por quartzo, seriam as estruturas características deste estágio nas encaixantes; diques de granitos e flancos de dobras boudinados; tension gashes preenchidas por granito associadas às falhas transcorrentes; indicadores cinemáticos, tais como dobras de arrasto, deslocamento dos corpos de granitos e estrias e ressaltos indicam movimento dextral.

Eby (1990) propôs uma distinção entre os granitos tipo-A anorogênicos e colisionais, baseandose nos teores dos elementos de ligação forte (HFSE) nessas rochas. Os granitos da área estudada são semelhantes ao grupo A2, que representa magmas derivados de crosta continental ou underplating, alojados durante ciclos de magmatismo colisional (Fig. 25).

Ao comparar-se as rochas estudadas com as supersuítes do Orógeno Araçuaí, verifica-se que os granitos estudados apresentam maiores similaridades com os granitos da Supersuíte G5 (Pedrosa Soares et al. 2011), os quais possuem elevados teores de $\mathrm{Ke} F e$, com uma assinatura pós-colisional, cálcio-alcalina à alcalina do tipo A2, associada ao relaxamento e colapso do orógeno.

Os dados aqui apresentados juntamente com os da literatura apontam que as intrusões ígneas estudadas representam os remanescentes de três estágios magmáticos na história do GPS:

- abertura da Bacia do Paraíba do Sul com a formação de basaltos tipo MORB-E;

- magmatismo básico calcio-alcalino alojado nos calcários do Grupo Paraíba do Sul e, posteriormente, metamorfizado e deformado conjuntamente no estágio sincolisional da Orogênese Brasiliana;

- magmatismo félsico transicional entre calcioalcalino normal ao de alto-K, alojado nos mármores durante estágio pós-colisional. No final desse estágio ocorreu o alojamento dos granitos alcalinos, marcando o final da Orogênese Brasiliana em tal região.

AGRADECIMENTOS Os autores agradecem ao Conselho Nacional de Desenvolvimento Científico e Tecnológico (CNPq), cujo apoio financeiro (Processo 476518/2007-5) permitiu a realização deste trabalho. Também agradecem ao revisor, cujas observações trouxeram relevantes contribuições ao artigo. 


\section{Referências}

Aitken B.G. 1983. T-XCO 2 stability relations and phase equilibria of a calcic carbonate scapolite. Geochimica et Cosmochimica Acta, 47(3):351-362.

Almeida F.F. 1977. O Cráton do São Francisco. Revista Brasileira de Geociências, 7(4):349-364.

Almeida F.F.M. \& Hasui Y. 1984. O Precambriano do Brasil. São Paulo, Edgar Blucher, 369 p.

Almeida F.F.M., Hasui Y., Brito Neves B.B., Fuck R.A. 1981. Brazilian Structural Provinces: an Introduction. Earth Science Reviews, 17:1-19.

Alkmim F.F., Marshak S. 1998. Transamazonian Orogeny in the Southern São Francisco Craton Region, Minas Gerais, Brazil: evidence for Paleoproterozoic collision and collapse in the Quadrilátero Ferrífero. Precambrian Research, 90:29-58.

Alkmim F.F., Marshak S., Pedrosa-Soares A.C., Peres G.G., Cruz S.C., Whittington A. 2006. Kinematic evolution of the Araçuaí-West Congo orogen in Brazil and Africa: Nutcracker tectonics during the Neoproterozoic assembly of Gondwana. Precambrian Research, 149:43-63.

Anderson J.L. 1980. Mineral equilibria and crystallization conditions in the Late Precambrian Wolf River rapakivi massif, Wisconsin. American Journal of Science, 280:389-332.

Anderson J.L. 1983. Proterozoic anorogenic granite plutonism of North America. In: Medaris Jr. L.G., Byers C.W., Mickelson D.M., Shanks W.C. (Eds.) Proterozoic Geology; Selected Papers from an International Proterozoic Symposium, Geological Society of America Memoir, 161:133-152.

Baker B.H., Goles G.G., Leeman W.P., Lindstrom M.M. 1977. Geochemistry and petrogenesis of a basaltbenmoreite-trachyte suite from the southern part of the Gregory Rift, Kenya. Contributions to Mineralogy and Petrology, 64:303-332.

Basaltic Volcanism Study Project. 1981. Basaltic Volcanism and the terrestial planets. New York, Pergamon Press, $1286 \mathrm{p}$.

Bastos Leal L.R., Teixeira W., Pecerillo E.M., Menezes Leal A.B., Girardi V.A.V. 1994. Geocronologia Rb/Sr e K-Ar do enxame de diques máficos de Uauá, Bahia (Brasil). Geochimica Brasiliensis, 8(1):99-114.

Bayer P., Schmidt-Thomé R., Weber-Diefenbach K., Horn H.A. 1987. Complex concentric granitoid intrusions in the Coastal Mobile Belt, Espírito Santo, Brazil: the Santa Angélica pluton - an example. Geologische Rundshau, 76:357-371.

Bilal E., Horn A.H., Nalini Jr. H.A., Mello F.M., CorreiaNeves J.M., Giret A.R., Moutte J., Fuzikawa K., Fernandes M.L.S. 2000. Neoproterozoic granitoid suites in southeastern Brazil. Revista Brasileira de Geociências, 30(1):51-54.

Bonin B., Azzouni-Sekkal A., Bussy F., Ferrag S. 1998. Alkali-calcic and alkaline post-orogenic-PO/ granite magmatism: petrologic constraints and geodynamic settings. Lithos, 45:45-70.
Bougault H. \& Treuil M. 1980. Mid-Atlantic Ridge - zero age geochemical variations between Azores and $22^{\circ} \mathrm{N}$. Nature, 286:209-212.

Bouvier A.S., Deloule E., Métrich N. 2010. Fluid inputs to magma sources of St. Vincent and Grenada (Lesser Antilles): new insights from trace elements in Olivine-hosted Melt inclusions. Journal of Petrology, 51(8):1597-1615.

Cabanis B. \& Lecolle M. 1989. Le diagramme La/10-Y/15$\mathrm{Nb} / 8$ : un outil pour la discrimination des séries volcaniques et la mise en evidence des processus de mélange et/ou de contamination crustales. Comptes Rendus de l'Académie des Sciences de Paris, 2(309):2023-2029.

Celino J.J., Botelho N.F., Pimentel M. M. 2000. Genesis of Neoproterozoic Granitoid Magmatism in the Eastern Araçuaí Fold Belt, Eastern Brazil: Field, Geochemical and $\mathrm{Sr}-\mathrm{Nd}$ Isotopic Evidence. Revista Brasileira de Geociências, 30:135-139.

Condie K.C. 2005. High field strength element ratios in Archean basalts: a window to evolving sources of mantle plumes? Lithos, 79:491-504.

Cordani U.G., Bernat M., Teixeira W., Kawashita K. 1974. Idades radiométricas das rochas alcalinas do Sul da Sabia. In: Congresso Brasileiro de Geologia, 28., SBG, Porto Alegre. Anais, 6:253-259.

Cox K.G., Bell J.D., Pankhurst R.J. 1979. The interpretation of igneous rocks. London, George Allen \& Unwin, 450 p.

Cunningham W.D., Alkmim F.F., Marshak S. 1998. A structural transect across the Coastal Mobile belt in the Brazilian Highlands (latitute 20(S): the roots of a Precambrian transpressional orogen. Precambrian Research, 92:251-275.

Dall'Agnol R., Teixeira N.P., Rämo O.T., Moura C.A.V., Macambira M.J.B., Oliveira D.C. 2005. Petrogenesis of the Paleoproterozoic rapakivi A-type granites of the Archean Carajás metallogenic province, Brazil. Lithos, 80:101-129.

De Campos C.M., Mendes J.C., Ludka I.P., Medeiros S.R., Moura J.C., Wallfass C. 2004. A review of the Brasiliano magmatism in southern Espírito Santo, Brazil, with emphasis on postcollisional magmatism. Journal of the Virtual Explorer. Disponível em: http:// virtualexplorer.com.au/journal/2004/17/campos. Acessado em: 05/03/2011.

DNPM. 2006. Anuário Mineral Brasileiro, Brasília, 34.

Eby G.N. 1990. The A-type granitoids: a review of their occurrence and chemical characteristics and speculations on their petrogenesis. Lithos, 26:115-134.

Faria L.F. 1997. Controle e tipologia de mineralizações de grafita flake do nordeste de Minas Gerais e sul da Bahia: uma abordagem regional. Dissertação de Mestrado, Universidade Federal de Minas Gerais, Belo Horizonte, Brasil.

Figueiredo M.C.H., Teixeira W. 1996. The Mantiqueira metamorphic complex, eastern Minas Gerais State: preliminary geochronological and geochemical results. Anais da Academia Brasileira de Ciências, 68:223-246. 
Fitton J.G., Saunders A.D., Norry M.J., Hardarson B.S., Taylor R.N. 1997. Thermal and chemical structure of Iceland plume. Earth and Planetary Science Letters, 153:197-208.

Fodor R.V., Vetter S.K. 1984. Rift-zone magmatism: Petrology of basaltic rocks transitional from CFB to MORB, southeastern Brazil margin. Contributions on Mineralogy and Petrology, 88:307-321.

Frost B. R., Barnes C.G., Collins W.J., Arculus R.J., Ellis D.J., Frost C.D. 2001. A geochemical classification for igneous rocks. Journal of Petrology, 42(11):2033-2048.

Geochemistry of igneous rocks. Disponível em: www. geokem.com. Acessado em: 19/04/2011.

Heilbron M., Machado N. 2003. Timing of terrane accretion in the Neoproterozoic-Eopaleozoic Ribeira orogen (SE Brazil). Precambrian Research, 125:87-112.

Heilbron M., Pedrosa-Soares A.C., Campos Neto M.C., Silva L.C., Trouw R.A.J., Janasi V.A. 2004. Província Mantiqueira. In: Mantesso-Neto V., Bartorelli A., Dal Ré Carneiro C., Brito Neves B.B. (Orgs.) Geologia do Continente Sul-Americano: Evolução da Obra de Fernando Flávio Marques de Almeida, Beca, p. 203-235.

Heilbron M., Duarte B.P., Valeriano C.M., Simonetti A., Machado N., Nogueira J.R. 2010. Evolution of reworked Paleoproterozoic basement rocks within the Ribeira belt (Neoproterozoic), SE-Brazil, based on $\mathrm{U}-\mathrm{Pb}$ geochronology: Implications for paleogeographic reconstructions of the São Francisco-Congo paleocontinent. Precambrian Research, 178:136-148.

Hickey R.L., Frey F.A., Gerlach D.C., López-Escobar L. 1986. Multiple sources for basaltic arc rocks from the Southern Volcanic Zone of the Andes $\left(34^{\circ}-41^{\circ} \mathrm{S}\right)$ : Trace element and isotopic evidence for contributions from subducted oceanic crust, mantle and continental crust. Journal Geophysical Research, 91(6):5963-5983.

Humphris S.E., Thompson G., Shilling J.G., Kingsley R.A. 1985. Petrological and geochemical variations along the Mid-Atlantic Ridge between $46^{\circ} \mathrm{S}$ and $32^{\circ} \mathrm{S}$ : influence of the Tristan da Cunha mantle Plume. Geochimica et Cosmochimica Acta, 49:1445-146.

Inda H.A.V. \& Barbosa J.F. 1978. Mapa geológico do Estado da Bahia. (Escala 1:1.000.000). Secretaria de Minas e Energia da Bahia, Brasil.

Irvine T.N. \& Baragar W.P.A. 1971. A guide to chemical classification of the common volcanic rocks. Canadian Journal Earth Science, 8:523-548.

Kay S.M., Ardolino A.A., Gorring M.L., Ramos V.A. 2007. The Somuncura Large Igneous Province in Patagonia: Interaction of a Transient Mantle Thermal Anomaly with a Subducting Slab. Journal of Petrology, 48(1):43-77.

Le Bas M.J. 2000. IUGS reclassification of the high-Mg and picritic volcanic rocks. Journal of Petrology, 41:1467-1470.

Liégeois J.P, Navez J., Hertogen J., Black R. 1998. Contrasting origin of post-collisional high-K calc-alkaline and shoshonitic versus alkaline and peralkaline granitoids. The use of sliding normalization. Lithos, 45:1-28.
Lopez-Escobar L., Vergara M., Frey F.A. 1981. Petrology and geochemistry of lavas from Antuco volcano, a basaltic volcano of the Southern Andes (37 $25^{\prime} \mathrm{S}$ ). Journal of Volcanology and Geothermal Research, 11:329-352.

Machado N., Valladares C., Heibron M., Valeriano C. 1996. $\mathrm{U}-\mathrm{Pb}$ geochronology of the central Ribeira Belt (Brazil) and implications for the evolution of the Brazilian Orogeny. Precambrian Research, 79:347-361.

Mendes J.C., Mcreath I., Wiedemann C.M., Figueiredo M.C.H. 1997. Charnoquitóides do maciço de Várzea Alegre: um novo exemplo do magmatismo de alto K no arco magmático do Espírito Santo. Revista Brasileira de Geociências, 27(1):13-24.

Mendes J.C., Medeiros S., Mcreath I., De Campos C. 2005. Cambro-Ordovician Magmatism in SE Brazil: U-Pb and $\mathrm{Rb}-\mathrm{Sr}$ ages combined with $\mathrm{Sr}$ and $\mathrm{Nd}$ isotopic data of charnockitic rocks from the Várzea Alegre Complex. Gondwana Research, 8:1-9.

Meschede M. 1986. A method of discriminating between different types of mid-ocean ridge basalts and continental tholeiites with the $\mathrm{Nb}-\mathrm{Zr}-\mathrm{Y}$ diagram. Chemical Geology, 16:207-218.

Modeland S., Francis D., Hynes A. 2003. Enriched mantle components in Proterozoic continental-flood basalts of the Cape Smith foldbelt, northern Québec. Lithos, 71:1-17.

Nakamura N. 1974. Determination of REE, Ba, Fe, Mg, $\mathrm{Na}$, and $\mathrm{K}$ in carbonaceous and ordinary chondrites. Geochimica et Cosmochimica Acta, 38:757-775.

Nalini Jr. H.A. 1997. Caracterization des suites magmatiques neoproterozoiques de la region de Conselheiro Pena et Galileia (Minas Gerais, Bresil). Tese de Doutorado, École des Mines de Saint Etienne, Saint Etienne, 237 p.

Nalini Jr H.A., Bilal E., Correia Neves J.M. 2000. Syncollisional peraluminous magmatism in the Rio Doce region: mineralogy, geochemistry and isotopic data of the Urucum suite (eastern Minas Gerais State, Brazil). Revista Brasileira de Geociências, 30:120-125.

Noce C.M., Machado N., Teixeira W. 1998. U-Pb geochronology of gneisses and granitoids in the Quadrilátero Ferrífero (southern São Francisco craton): age constraints for Archean and Paleoproterozoic magmatism and metamorphism. Revista Brasileira de Geociências, 28(1):95-102.

Noce C.M., Macambira M. B., Pedrosa-Soares A. C. 2000. Chronology of Neoproterozoic-Cambrian granitic magmatism in the Araçuaí Belt, Eastern Brazil, based on single zircon evaporation dating. Revista Brasileira de Geociências, 30:25-29.

Noce C.M, Pedrosa-Soares A.C., Piuzana D., Armstrong R., Laux J.H., Campos C., Medeiros S.R. 2004. Ages of sedimentation of the kinzigitic complex and of a late orogenic termal episode in the Araçuaí orogen, northern Espírito Santo State, Brazil: Zircon and monazite U-Pb SHRIMP and ID-TIMS data. Revista Brasileira de Geociências, 349:587-592. 
Pearce J. 1996. Sources and settings of granitic rocks. Episodes, 19(4):120-125.

Pearce J.A., Harris N.B.W., Tindle A.G. 1984. Trace element discrimination diagrams for the tectonic interpretation of granitic rocks. Journal of Petrology, 25:956-983.

Peccerillo A., Taylor S.R. 1976. Geochemistry of Eocene calc-alkaline rocks from Kastamonu area, Northern Turkey. Contributions to Mineralogy and Petrology, 58:63-81.

Pedrosa Soares A.C. 1995. Potencial aurífero do Vale do Araçuaí, Minas Gerais: história da exploração, geologia e controle tectono-metamórfico. Tese de Doutoramento, Universidade de Brasília, Brasília.

Pedrosa Soares A.C., Noce C.M. 1999. The Araçuaí-West Congo Orogen: alpyne, Himalayan-type, or neither? In: VII Simpósio Nacional de Estudos Tectônicos, SBG Lençóis, Anais, p. 30-33.

Pedrosa-Soares A.C. \& Noce C.M. 1998. Where is the suture zone of the Neoproterozoic Araçuaí-WestCongo orogen? In: Conference on Basement Tectonics, 14, Ouro Preto, UFOP, Extended Abstracts, p. 35-37.

Pedrosa Soares A.C. \& Wiedemann-Leonardos C.M. 2000. Evolution of the Araçuaí Belt and its connection to the Ribeira Belt, eastern Brazil. In: Cordani U. (ed.). Tectonic evolution of South America, $31^{\text {st }}$ IGC, p. 265-285.

Pedrosa Soares A.C., Noce C.M., Wiedemann C.M., Pinto C.P. 2001. The Araçuaí-West Congo orogen in Brazil: an overview of a confined orogen formed during Gondwanaland assembly. Precambrian Research, 110:307-323.

Pedrosa Soares A.C., Queiroga G., Gradim C.T., Roncato J.G., Novo T.A., Jacobsohn T., Silva K.L. 2006. Folha Mantena. Programa Geologia do Brasil, CPRM Serviço Geológico do Brasil, Rio de Janeiro, Brasil.

Pedrosa Soares A.C., Alkmim F.F., Tack L., Noce C.M., Babinski M., Silva L.C., Martins-Neto M.A. 2008. Similarities and differences between the Brazilian and African counterparts of the Neoproterozoic AraçuaíWest Congo orogen. In: Pankhurst R.J., Trouw R. A.J., Brito Neves B.B., De Wit M.J. (eds) West Gondwana: Pre-Cenozoic Correlations Across the South Atlantic Region. London, Geological Society, Special Publications, 294, p. 153-172.

Pedrosa-Soares A.C., De Campos C.P, Noce C., Silva L.C., Novo T., Roncato J., Medeiros S., Castañeda C., Queiroga G., Dantas E., Dussin I., Alkimin F. 2011. Granitic magmatism and related mineral deposits in the Araçuaí orogen, SE Brazil. In: Sial A.N. (ed). Granitic Magmatism and Related Mineral Deposits, Geological Society of London Special Publication, 350, p. 25-51.

Picard C., Monzier M., Eissen J.P., Robin C. 1995. Concomitant evolution of tectonic environment and magma geochemistry, Ambrym volcano (Vanuatu, New Hebrides arc). In: Smellie J.L. (eds). Volcanism Associated with Extension at Consuming Plate Margins. Geological Society American Special Publication, 81:135-154.
Pinto C.P., Drumond J.B., Féboli W.L. 2001. Projeto Leste, Etapas 1 E 2. CODEMIG, Belo Horizonte, Brasil.

Ragatky D., Tupinambá M., Heilbron M., Santos Marins G. 2003. Isotopic data ( $\mathrm{sr}$ and nd) from the Paraíba do Sul group orthoamphibolites. In: South American Symposium on Isotope Geology, 4, Salvador. Short Papers..., p. 260-263.

Ragatky D., Tupinambá M., Paschoal Duarte B. 2000. Sm/ $\mathrm{Nd}$ data of metasedimentary rocks from the central segment of Ribeira belt, southeastern Brazil. Revista Brasileira de Geologia, 30(1):165-168.

Santos Marins G. \& Duarte B.P. 2000. Petrografia, geoquímica e ambientes tectônicos dos anfibolitos da Klippe Paraiba do Sul, setor central da Faixa Ribeira. In: Congresso Brasileiro de Geoquímica, 8, Curitiba. CD room.

Schilling J.G., Meyer P.S., Kingsley R.H. 1983. Rare earth geochemistry of Iceland basalts: spatial and temporal variations. In: Bott M.H.P., Saxov S., Talwani M., Thiede J. (eds). Structure and devolopment of the Greenland Scotland Ridge. Plenum Press, New York and London, p. 319-342.

Sengupta P. \& Ray J. 2010. Petrogenesis of flood basalts of the Narsingpur-Harrai-Amarwara-Lakhnadon section of eatern Deccan Province, India. In: Ray J., Gautam S., Biswajit G. (eds). Topics in Igneous Petrology. Springer, p. 191-239.

Siga Jr. O., Tassinari C.G., Van Schmus W.R. 1989. Caracterização geocronológica de maciços charnoquíticos do sudeste brasileiro. In: Simpósio de Geologia do Sudeste, 1, Rio de Janeiro. Bol. Resumos, p. 90-91.

Silva J.N. 1993. Programa Levantamento Geológicos Básicos do Brasil. Cachoeiro de Itapemirim. Folha SF.24V-A-V. Estado do Espírito Santo. Escala 1:100.000. Brasília, DNPM/CPRM. 176 p., ilustração, 2 mapas.

Silva da L.C., Hartmann L.A., McNaughton N.J., Fletcher I. 2000. Zircon U/Pb SHRIMP dates Neoproterozoic overprinting in Paleoproterozoic granitic-gneissic terranes, southern Brazil. American Mineralogist, 85:649-667.

Silva L. C., Pedrosa-Soares A. C., Teixeira L. R. 2008. Tonian rift-related, A-type continental plutonism in the Araçuaí orogen, Eastern Brazil: new evidences for the breakup stage of the São Francisco-Congo Paleocontinent. Gondwana Research, 13:527-537.

Söllner H.S., Lammerer B., Weber-Diefenbach K. 1991. Die Krustenentwicklung in der Kusten region nördlich von Rio de Janeiro, Brasilien. Müncher Geologische Hefte, 4:1-100.

Sinton J.M., Ford L.L., Chapell B., McCulloch M.T. 2003. Magma genesis and mantle heterogeneity in the Manus back-arc basin, Papua New Guinea. Journal of Petrology, 44(1);159-195.

Sun S.S. \& McDonough W.F. 1989. Chemical and isotopic systematics of oceanic basalts: implications for mantle compositions and processes. In: Saunders A. D. \& Norry M. J. (eds). Magmatism in the ocean basins. Geological Society London, 313-345. 
Sylvester P.J. 1989. Post-collisional alkaline granites. Journal of Geology, 97:180-261.

Teixeira W. 1985. Aevoluçãogeotectônica da porçãomeridional do Craton do São Francisco com base em interpretações geocronológicas. Tese de Doutorado, Instituto de Geociências, Universidade de São Paulo, 207 p.

Vieira V.S. 1997. Programa Levantamentos Geológicos Básicos do Brasil. Baixo Guandu, Folha SE. 24-Y-C-V. DNPM/CPRM, Brasília, p. 175.

Wang Q., McDermott F., Xu J.F., Bellon H., Zhu Y.T. 2005. Cenozoic K-rich adakitic volcanic rocks in the Hohxil area, northern Tibet: Lower-crustal melting in na intracontinental setting. Geology, 33:465-468.

Wiedemann C. 1993. The evolution of the early Paleozoic, late to post-collisional magmatic arc of the Coastal mobile belt in the State of Espirito Santo, eastern Brazil. Anais da Academia Brasileira de Ciências, 65:163-181.

Wiedemann C.M., Mendes J.C, Moura J.C., Costa Nascimento R.C., Ludka I.P. 1997. Granitoids of the Espírito Santo Magmatic Arc. In: Int. Symp. Granites and Associated Mineralizations, 2, Salvador. Excursion Guide, 57-76.
Wiedemann C.M., Medeiros S.R., Ludka I.P., Mendes J.C., Costa de Moura J. 2002. Architecture of late orogenic plutons in the Araçuaí- Ribeira fold belt, southeast Brazil. Gondwana Research, 5(2):381-399.

Wilson M.J. 1989. Igneous Petrogenesis. A Global Tectonic Approach. London, Boston, Sydney, Wellington, Unwin Hyman, 466 p.

Winchester J.A., Floyd P.A. 1977. Geochemical discrimination of different magma series and their differentiation products using immobile elements. Chemical Geology, 20:325-343.

Wood D.A., Joron J.L., Treuil M. 1979a. A re-appraisal of the use of trace elements to classify and discriminate between magma series erupted in different tectonic settings. Earth Planetary Science Letters, 45:326-336.

Yardley B.W.D. 1994. An introduction to metamorphic petrology, Harlow, Longmans, 248 p.

Manuscrito ID 22655

Recebido em: 22/08/2011

Aprovado em: 07/03/2012 